\title{
REABILITAÇÃO VESTIBULAR DA VERTIGEM POSTURAL PAROXÍSTICA BENIGNA DE CANAL POSTERIOR EM IDOSOS
}

ANA PAULA DO REgo ANDRÉ 


\section{UNIVERSIDADE DE SÃO PAULO \\ FACULDADE DE MEDICINA DE RIBEIRÃO PRETO}

\section{REABILITAÇÃO VESTIBULAR DA VERTIGEM \\ POSTURAL PAROXÍSTICA BENIGNA DE CANAL \\ POSTERIOR EM IDOSOS}

Dissertação apresentada à
Faculdade de Medicina de
Ribeirão Preto da Universidade de
São Paulo para obtenção do grau
de Mestre em Biociências
Aplicada à Clínica Médica Área de
Concentração: Clínica Médica

Aluna: Ana Paula do Rego André Orientador: Prof. Dr. Júlio Cesar Moriguti

\section{RIBEIRÃO PRETO}


André, Ana Paula do Rego

Reabilitação Vestibular da Vertigem Postural Paroxística Benigna de Canal Posterior em Idosos. Ribeirão Preto, 2003.

69 p.: il. ; $28 \mathrm{~cm}$

Dissertação apresentada à Faculdade de Medicina de Ribeirão Preto/ USP, Departamento de Clínica Médica Sub-área: Biociências aplicada à Clínica Médica.

Orientador: Moriguti, Júlio Cesar

1.Vertigem 2. Reabilitação vestibular 3. Vertigem Postural Paroxística Benigna 


\section{Dedicatórias}


Dedico este trabalho a memória de meu pai Rubens do Rego, que onde quer que esteja, fez parte do início deste sonho, não podendo agora, dividir a sua conclusão.

Pai, minha gratidão pela educação e todos os valores que você , juntamente com minha mãe me proporcionou.

Dedico e agradeço pelas recordações de duas pessoas que amei muito e que talvez eu não tenha tido tempo de dizer à elas o quanto (...) e hoje não as tenho mais aqui( ...) Agradeço mesmo com dor e lágrimas nos olhos, a felicidade de ter amado e convivido com vocês minha irmã Laura Aparecida do Rego Campos e você meu sobrinho Felipe Campos. Que Deus olhe por vocês sempre!!

"O Senhor é meu Pastor, nada me faltará. Ele me faz repousar em campos verdejantes. Leva-me para junto das águas de descanso. Guia-me pelas veredas da justiça"

(Salmo 23:1, 2) 
Agradecimentos 


\section{À Deus,}

Pela força que me passa, nas horas difíceis, e na paz e calma que me transmite nos momentos bons, me guiando e não me deixando desistir deste trabalho e de todos meus sonhos, apesar das dificuldades vividas (...)

“Debaixo do céu há momento para tudo e tempo certo para cada coisa (...) Tudo o que Ele fez é apropriado para cada tempo (...)

Compreendi que tudo o que Deus fez dura para sempre." (Eclesiastes 3:1, 11 e 14) 
Aos meus pais, Rubens do Rego e Rute Maria Paiva do Rego,

Minha eterna gratidão pelos valores ensinados, pelo amor incondicional, pelo respeito e pela compreensão.

"Honra teu pai e tua mãe, para que se prolongue os teus dias na terra que o senhor, teu Deus, te dá" (Êxodo 20-12) 
À Minha mãe,

Agradeço à minha mãe, Rute Maria Paiva do Rego, pela força e coragem que tem, mulher imbatível pelas dificuldades e ausências. Agradeço à você mãe, por você existir, sendo um espelho, exemplo de vida e de coragem a ser seguido. Agradeço, ainda, pelos momentos que se privou de outros afazeres e me ajudou nas traduções dos textos.

\section{"Seu caráter é o resultado do seu procedimento." (Aristóteles)}


Ao meu esposo,

Agradeço ao meu esposo Miguel Angelo Gonçalves André pelo incentivo diante de todas as dificuldades que a vida me impôs. Você é meu porto seguro... à você a minha eterna gratidão por compartilhar todos os momentos de minha vida e por ter me dado o meu maior orgulho(...) nosso filho Diego. Amo você!!!

“Porque onde está o teu tesouro, lá também está teu coração"

(Mateus 6:21) 
Ao meu filho,

Meu pequeno Diego me perdoe pelas correrias e pelas ausências em alguns momentos importantes de seu desenvolvimento. Com certeza tudo que faço é pensando no melhor para você e nossa família, mesmo que eu erre, erro tentando acertar. Obrigada por você ser o "meu bebê".

“Instruir o menino no caminho em que deve andar, e, até quando envelhecer, não se desviará dele" (Provérbios 22-6)

"Podemos convencer alguém pelo que somos, nunca pelo que dizemos"

(H. Rohden) 
À minha sobrinha,

Agradeço por sua existência, minha afilhada e sobrinha Ana Carolina Campos, e que na triste ausência de sua mãe, me esforço a cada dia para ser um bom exemplo para você.

“A vida não é um corredor reto e tranqüilo que nós percorremos livres e sem empecilhos, mas um labirinto de passagens, pelas quais nós devemos procurar nosso caminho, perdidos em confusos, de vez em quando presos em um beco sem saída.

Porém, se tivermos fé uma porta sempre será aberta para nós, não talvez aquela sobre a qual nós mesmos nunca pensamos, mas aquela que definitivamente se revelará boa para nós."
(A. J. Cronin) 
Aos Idosos,

Obrigada por fazerem parte deste estudo e pela confiança depositada em meu trabalho.

“Desde os seis anos que eu tinha a mania de desenhar a forma das coisas. Quando estava com 50 anos, havia publicado uma infinidade de desenhos; mas tudo que produzi antes dos 70 não é digno de ser levado em conta. Aos 73 anos aprendi um pouco sobre a verdadeira estrutura da natureza, dos animais, plantas, pássaros, peixes e insetos. Em conseqüência, quando estiver com 80 anos, terei realizado mais progressos. Aos 90 penetrarei no mistério das coisas. Aos 100,por certo, terei atingido uma fase maravilhosa. E quando fizer 110 anos, qualquer coisa que eu fizer, seja um ponto ou uma linha, terá vida".

Hosukaj (pintor japonês) 
Ao Prof. Dr. Júlio Cesar Moriguti, pelo incentivo, compreensão e disponibilidade na realização deste trabalho. Obrigada pela confiança depositada em todos os momentos, pelas horas dispensadas na leitura e correções.

Ao Prof. Dr. José Fernando Colafêmina por me apresentar o tema reabilitação vestibular e fazer o desafio de implantar esse serviço no setor de fonoaudiologia. Obrigada pela colaboração na melhoria deste trabalho após suas correções. A semente semeada há algum tempo, hoje, está dando seu fruto mais rico e esperado: essa dissertação. Obrigada por poder contar com sua sabedoria, simplicidade e disponibilidade.

Ao Prof. Dr. Fernando Freitas Ganança obrigada pelas sugestões extremamente pertinentes durante a correção deste trabalho. Agradeço pela sua disponibilidade e atenção.

Ao Prof. Dr. Gerson Muccillo pela disponibilidade nas orientações e contribuições estatísticas.

"O conhecimento não é sabedoria... A aprendizagem só em si não é sabedoria A sabedoria é a aplicação do conhecimento e dos fatos. A sabedoria é dá-se conta de que você não sabe nada. A sabedoria é dizer: "minha mente está aberta, onde quer que eu esteja, estou apenas começando". Há cem vezes mais coisas a perceber do que o que conheço. Isso é o princípio da sabedoria ..."

Buscaglia 
A todas as fonoaudiólogas do setor de fonoaudiologia do Hospital das Clínicas da Faculdade de Medicina de Ribeirão Preto, pelo companheirismo, pelas dúvidas sanadas e apoio concedido.

Em especial às amigas e fonoaudiólogas Luciana Vitaliano Voi Trawitzki e Paula Issa pela presença em todas as horas, pelas críticas, apoio e experiência transmitida.

À secretária do Setor de Fonoaudiologia Juliana Reche que muito colaborou na remissão de dúvidas de digitação.

Ao jovem Leandro Rodrigues Cucco pela elaboração das ilustrações.

À minha prima e amiga Stela Maris Penacchi Piere por sua disponibilidade em dividir seu vasto conhecimento da língua inglesa.

À fonoaudióloga aperfeiçoanda Erika B. Mantello por sua ajuda nos diferentes estágios deste trabalho.

À fonoaudióloga e amiga Andréa Pires Corrêa pela disponibilidade em todos os momentos.

Ao Dr. Issa por sua atenção na leitura e correção deste trabalho.

Ao meu cunhado Thiago Gustavo G. André por sua ajuda e disponibilidade durante a realização deste trabalho.

A todos que direta ou indiretamente colaboraram na elaboração deste trabalho.... meu muito obrigada!!!!! 
Desumo 


\section{RESUMO}

A Reabilitação Vestibular (RV) é um programa de tratamento realizado por exercícios, associado a um conjunto de medidas relacionadas à mudança de hábitos e esclarecimentos sobre os sintomas associados à alteração do equilíbrio. É um método de terapia fisiológico, inócuo e coerente, que pretende trabalhar o paciente vertiginoso aliviando os sintomas e aumentando seu limiar de sensibilidade para a vertigem.

A Vertigem Postural Paroxística Benigna (VPPB) é a mais comum das vestibulopatias periféricas em adultos, principalmente em idosos do sexo feminino, apresentando como etiologia mais comum a degeneração da mácula utricular. Nos idosos, caracteriza-se por tontura rotatória e nistagmo posicional à mudança de posição da cabeça ou por determinada posição do corpo e, como consequiência, pode ocorrer quedas e limitações na qualidade de vida dos mesmos, tornando-os limitados físico e emocionalmente.

O presente estudo teve como objetivo avaliar prospetivamente a Reabilitação Vestibular como tratamento da VPPB com acometimento de canal semicircular posterior e seu efeito na qualidade de vida em indivíduos idosos.

Participaram do estudo 23 voluntários com hipótese diagnóstica otorrinolaringológica de VPPB de canal semicircular posterior por ductolitíase, com faixa etária entre 60 e 91 anos, com média de 70,69 anos e desvio padrão de 9,24.

Quanto ao gênero $17(73,9 \%)$ eram do sexo feminino e $6(26,1 \%)$ do masculino. No tratamento da VPPB por meio da reabilitação vestibular em 17 $(73,9 \%)$ dos voluntários, utilizou-se a manobra de Epley; 6 (26,08\%) com manobra 
de Epley associada ao exercício de Brandt e Daroff . O tempo de tratamento variou de 2 a 6 semanas.

Aplicou-se um questionário (Dizziness Handicap Inventory - DHI brasileiro) pré e pós RV para quantificar a tontura quanto aos aspectos: físico, emocional, funcional e geral.

Quanto ao aspecto físico, emocional, funcional e geral observou-se diferença estatisticamente significativa ( $\mathrm{p}<0,0001)$ entre os escores pré e pós $\mathrm{RV}$.

Concluímos que os escores dos aspectos avaliados no DHI brasileiro melhoraram após intervenção fonoaudiológica pela RV nos pacientes com VPPB de canal semicircular posterior, havendo um incremento na qualidade de vida dos voluntários estudados. 
Abstract = 


\begin{abstract}
Vestibular rehabilitation is a treatment's program based on exercises, associated with a factor's collection related to changing habits and guidance about symptoms associates to unbalance. It is harmless, coherent and physiologic therapy method that intends to work the dizzy patient, relieving the symptoms and increasing his vertigo's threshold.
\end{abstract}

The Benign Paroxysmal Positional Vertigo is the one most frequent adult's pathologies of the peripheral vestibular's system. It is caused by the utricle's degeneration. In aged people, is characterize by vertigo and positional nystagmus provoked by certain cephalic movements or body movements and, as sequelae, can take to falls and life quality restriction, physical and emotional.

This study's purpose was evaluate the Vestibular Rehabilitation in posterior canal's BPPV's treatment and its effect in the elderly life's quality.

Twenty three volunteers with BPPV's posterior canal's canalith diagnoses pointed out by otorhinolaryngologist, aged between sixty to ninety one years old, average of 70,69 years and deviation of 9,24.

Seventeen volunteers $(73,9 \%)$ were female and six $(26,1 \%)$ were male. In BPPV's treatment by vestibular rehabilitation, thirteen $(56,52 \%)$ were submitted to Epley maneuver, six $(26,08 \%)$ used the Epley maneuver associated to Brandt- Daroff exercises and four patients $(17,39 \%)$ were submitted only to the Brandt- Daroff exercises. The treatment's time lasted from 2 to 6 weeks.

A questionnaire (Dizziness Handicap Inventory Portuguese- DHI Portuguese) was used in order to dizziness quantity in the physical, emotional, functional and 
general aspects, which was observed a significant statistical difference $(\mathrm{p}<0,001)$ between the scores previous and after Vestibular Rehabilitation.

Concluding that the aspects' scores evaluated improved after Vestibular Rehabilitation therapy in the posterior canal's BPPV's patients, occurring an improvement in volunteers' life quality. 
SUMÁRIO

RESUMO

ABSTRACT

LISTAS

1 INTRODUÇÃO

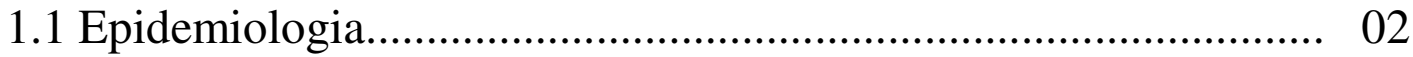

1.2 O Sistema Vestibular.............................................................. 05

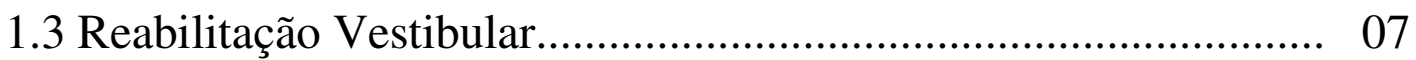

1.4 Vertigem Postural Paroxística Benigna........................................ 11

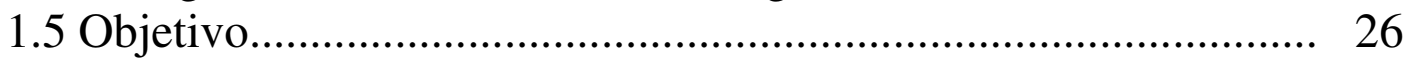

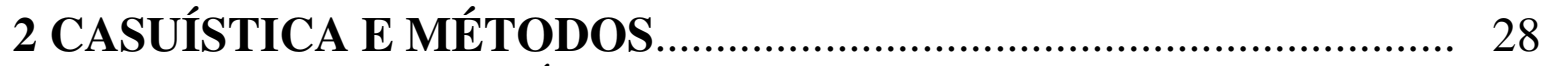

2.1 Considerações Éticas.............................................................. 29

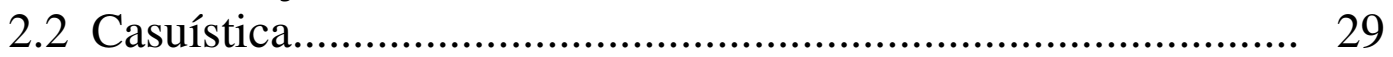

2.3 Coleta de Dados.................................................................. 30

2.4 Análise estatística.................................................................. 36

3 RESULTADOS

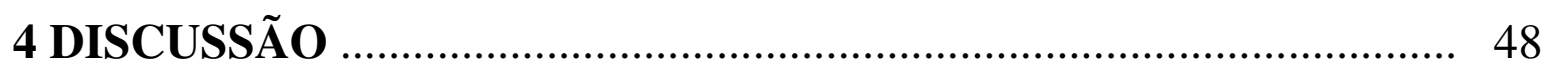

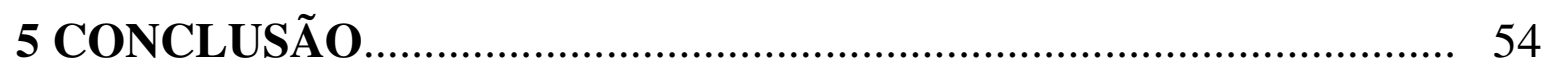

6 REFERÊNCIAS BIBLIOGRÁFICAS............................................. 57

ANEXOS 


\section{Lista de Figuras}

Figura 1 - Labirinto membranoso...................................................... 06

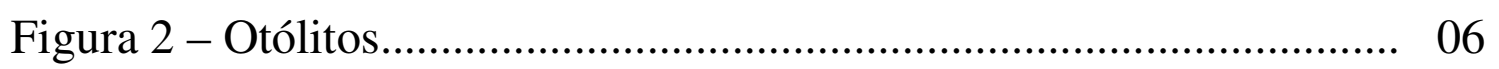

Figura 3 - Substrato fisiopatológico da VPPB canalitíase- cupulolitíase. 13

Figura 4 - Demonstração da Manobra de Dix- Hallpike.......................... 16

Figura 5- Demonstração do exercício de Brandt- Daroff......................... 17

Figura 6 - Demonstração da manobra de Epley......................................... 22

Figura 7- Demonstração da posição para dormir no período de 48 horas após a colocação do colar cervical.......................................... 25

Figura 8- Fluxograma de atendimento da VPPB............................... 33 


\section{Lista de Quadros}

Quadro 1- Substrato fisiopatológico do acometimento dos canais verticais.. 14

Quadro 2 - Possíveis resultados do teste de Dix- Hallpike. 15

Quadro 3 - Sugestões de realização do exercício de Brandt- Daroff segundo os mesmos autores

Quadro 4 - Descrição dos 23 voluntários quanto à idade, gênero, diagnóstico e lado acometido. 40

Quadro 5 - Descrição dos 23 voluntários quanto ao escore físico, emocional, funcional e geral do DHI Pré e Pós RV. 44 


\section{Lista de Tabelas}

Tabela 1 - Valores dos escores do aspecto físico dos 23 voluntários Pré Reabilitação Vestibular ( Pré RV) e Pós reabilitação vestibular (Pós RV)

Tabela 2 - Valores dos escores do aspecto funcional dos 23 voluntários Pré Reabilitação Vestibular ( Pré RV) e Pós reabilitação vestibular (Pós RV)

Tabela 3 - Valores dos escores do aspecto emocional dos 23 voluntários Pré Reabilitação Vestibular ( Pré RV) e Pós reabilitação vestibular (Pós RV)

Tabela 4 - Valores dos escores do aspecto geral dos 23 voluntários Pré Reabilitação Vestibular ( Pré RV) e Pós reabilitação vestibular (Pós RV)

Tabela 5- Correlações entre os aspectos físico, emocional, funcional, geral e idade

Tabela 6 - Correlações entre a idade e a diferença de escores dos aspectos físico, funcional, emocional e geral pré e pós Reabilitação Vestibular

Tabela 7 - Associações entre o gênero e a diferença de escores dos aspectos físico, funcional, emocional e geral pré e pós Reabilitação Vestibular 


\section{Lista de Abreviaturas}

RV- Reabilitação Vestibular

VPPB- Vertigem Postural Paroxística Benigna

DHI- Dizziness Handicap Inventory

MRC- Manobra de reposição Canalítica

Pré RV- Pré Reabilitação Vestibular

Pós RV- Pós Reabilitação Vestibular 
$\lceil$ ntrodução 


\section{1- INTRODUÇÃO}

\subsection{Epidemiologia}

Os seres vivos são regidos por um determinismo biológico: todos nascem, crescem, amadurecem, envelhecem, declinam e morrem. O tempo e a forma que se processam essas fases dependem de cada indivíduo, da programação genética de sua espécie e de fatores ambientais (habitat, modus vivendi e de agressões que tenham sofrido no decorrer de sua existência) ${ }^{(1)}$.

De acordo com os dados divulgados pelo Instituto Brasileiro de Geografia e Estatística - IBGE (1996) ${ }^{(2)}$, a população geriátrica está aumentando rapidamente. Tal crescimento tem sido atribuído às mudanças do padrão reprodutivo no Brasil, causado principalmente por duas razões: a primeira diz respeito ao crescente processo de urbanização que ocorreu nos últimos 40 anos, o país passou de uma população predominantemente rural para urbana, e uma das principais conseqüências desse fato relaciona-se com a crescente limitação do tamanho da família, imposta pelo "modus vivendi" dos grandes centros urbanos. A segunda razão diz respeito ao aumento da população feminina mais receptiva ao planejamento familiar e com mais acesso aos meios contraceptivos. Em função destas duas razões, tem-se verificado uma constante diminuição das taxas de fecundidade que, no período entre 1965 e 1982, apresentaram uma queda de 30,4\%. Prova evidente dessa queda é que, enquanto em 1960 o número de filhos por mulher era de 6,2, em 1970, ficou em 5,6, em 1980 o nível reduziu para 4,5.

Após 1980, esta fecundidade continuou a declinar e, em 1984, foi estimada em 3,5 filhos por mulher, ou seja, em apenas 4 anos a população brasileira registrou 
uma redução sem precedentes em sua fecundidade. Uma consequiência imediata do processo de redução da fecundidade, iniciado na década de 60, é o envelhecimento da população.

A população de jovens de menos de 15 anos de idade, que representavam 42\% do total entre 1950 e 1970, reduziu seu peso relativo para 39\% em 1980. Paralelamente à redução da taxa de fecundidade, existem outros fatores como, por exemplo, a diminuição da taxa de mortalidade que, juntos, acabam se traduzindo numa elevação da expectativa média de vida da população e num aumento em termos absolutos e proporcionais do número de pessoas que atingem idades avançadas ${ }^{(3)}$.

Todos os estudos demográficos apontam que a taxa de crescimento do contingente de idosos ultrapassa, em muito, a taxa de crescimento da população total.

Além das implicações sócio-econômicas e de saúde pública, o envelhecimento populacional implica em conseqüências evidentes sobre a manutenção da qualidade de vida, preocupação constante do médico e de outros profissionais da área de saúde. Este conceito tem como base a autonomia e funções da vida diária da pessoa, em oposição à idade cronológica. Com o envelhecimento, é cada vez mais freqüente o aparecimento de múltiplas doenças, com conseqüente surgimento de incapacitações e aumento progressivo do grau de dependência. A compreensão do processo do envelhecimento e das doenças de alta prevalência nesta faixa etária, com o desenvolvimento de métodos de prevenção, mostra-se primordial para a possibilidade da manutenção da capacidade funcional e para a conseqüente melhoria da qualidade de vida individual e coletiva. A manutenção do menor grau de incapacidade e do maior grau de independência depende da atuação adequada de profissionais (de múltiplas áreas de saúde) especificamente treinados ${ }^{(4)}$. 
A vertigem pode derivar de doenças que atingem diretamente o sistema vestibular ou pode resultar de afecções outras que atingem o sistema indiretamente ${ }^{(5)}$.

O principal sintoma decorrente da disfunção do sistema vestibular na população idosa é a tontura rotatória, que pode, ou não, estar associada a outro tipo de tontura ${ }^{(6)}$

A partir dos 65 anos de idade, este sintoma torna-se uma queixa freqüente nos consultórios médicos e pode estar associada a outras disfunções como as auditivas e as manifestações neurovegetativas ${ }^{(7,8)}$.

A prevalência é maior no sexo feminino, principalmente com o aumento da idade $^{(9,10)}$ e as duas mais freqüentes afecções do sistema vestibular na população idosa são a vertigem postural paroxística benigna e a doença de Ménière. Muitos são os sintomas que podem estar associados às vertigens e a outros tipos de tontura ${ }^{(11)}$.

Conforme Cohen ${ }^{(12)}$; Araújo $^{(13)}$, a redução da função do sistema vestibular na população com idade superior a sessenta anos pode promover uma vida sedentária ou muito dependente, além de gerar um forte impacto psicológico que, conseqüentemente, produz diminuição da qualidade de vida.

Segundo Ganança et al. ${ }^{(11)}$, em um estudo sobre a prevalência de sintomas pela história clínica de mil pacientes consecutivos, em Ambulatório de Otoneurologia, foi observado que praticamente um a cada quatro/cinco indivíduos com vertigem ou outro tipo de tontura, apresentava zumbido ( $1^{\circ}$ sintoma associado na ordem de prevalência) e/ou hipoacusia ( $2^{\circ}$ sintoma mais comum) concomitantes.

De acordo, ainda, com um estudo realizado por Ganança et $a l .{ }^{(7)}$, a tontura é o segundo sintoma em prevalência até os 65 anos, sendo o mais freqüente após esta idade e cerca de $42 \%$ da população adulta o refere em alguma época de sua vida. 
Em virtude das inter-relações entre o sistema vestibular e as diversas áreas do sistema nervoso central, indivíduos com tontura geralmente relatam dificuldade de concentração mental, perda de memória, fadiga, insegurança psíquica devido à insegurança física, irritabilidade, perda da autoconfiança, ansiedade, depressão e/ou pânico $^{(14)}$.

\subsection{O Sistema Vestibular}

O sistema vestibular periférico inclui os labirintos membranoso e ósseo, e os sensores do movimento do sistema, as células ciliadas ${ }^{(15)}$.

O labirinto ósseo é constituído pelo vestíbulo, três canais semicirculares e pela cóclea. O labirinto membranoso (figura 1) está suspenso dentro do labirinto ósseo pela perilinfa. Contém cinco órgãos sensoriais: sáculo e utrículo alojado no vestíbulo, e os três ductos semicirculares alojados nos respectivos canais semicirculares. As máculas do sáculo e utrículo são formadas por células de sustentação e células ciliadas que são estimuladas especificamente por acelerações lineares do movimento. Tais células mergulham em substância gelatinosa chamada de membrana otolítica, que por sua vez, contém em seu interior pequenas concentrações de carbonato de cálcio (figura 2) denominadas otólitos ou otocônias (15)

Ainda de acordo com Hain ${ }^{(16)}$, os otólitos registram forças relacionadas ao movimento linear e respondem a este tipo de aceleração, enquanto os canais semicirculares reagem ao movimento angular. 


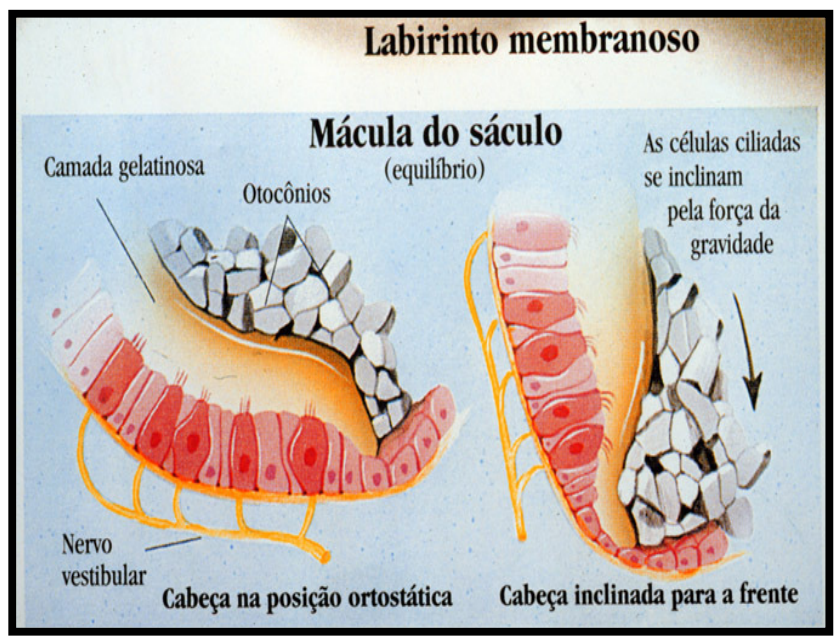

Figura 1 : Labirinto membranoso

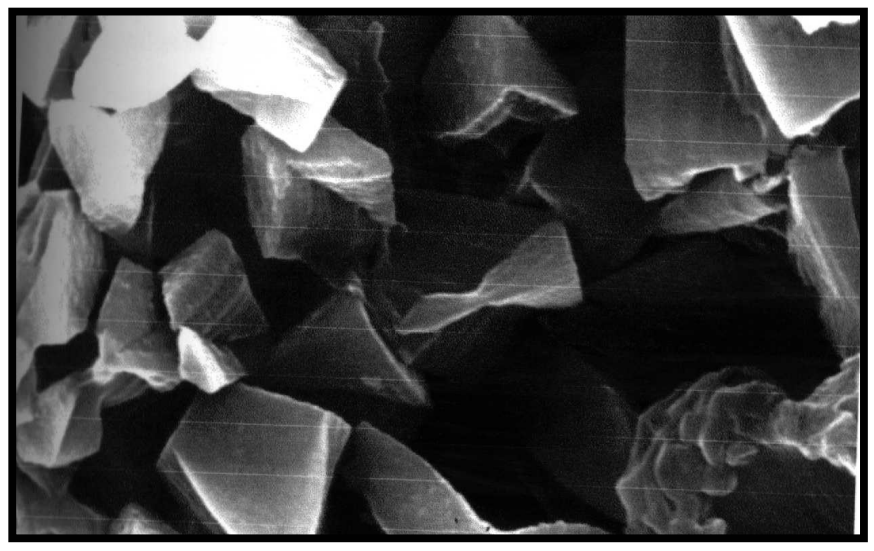

Figura 2: Otólitos ${ }^{(17)}$

Os distúrbios do equilíbrio apresentados pelos idosos diminuem consideravelmente sua capacidade funcional ${ }^{(13)}$.

A maior prevalência em idosos pode ser explicada pela alta sensibilidade dos sistemas auditivo e vestibular aos problemas clínicos situados em outras partes do corpo humano e ao processo de deterioração funcional destes sistemas com o envelhecimento $^{(14)}$. 
Outras alterações no sistema vestibular incluem degeneração das otocônias dentro do sáculo e utrículo, o que seria a causa do aparecimento da vertigem postural paroxística benigna em idosos ${ }^{(17)}$.

\subsection{Reabilitação Vestibular}

Segundo Barbosa et al. ${ }^{(18)}$, a Reabilitação Vestibular (RV) foi criada na Inglaterra, em 1946, por Sir Terence Cawthone, que contava com a ajuda de um renomado fisioterapeuta, F.S. Cooksey.

Estes foram os primeiros autores a descreverem exercícios como método de reabilitação vestibular no King's College Hospital em Londres, quando trabalhando no atendimento de emergência observaram melhora da tontura em vítimas de trauma cranioencefáfico, quando os mesmos incentivavam pacientes a movimentarem a cabeça e olhos livremente em todas as direções, começando gradualmente e mantendo os mesmos se os pacientes sentissem tontura ${ }^{(18)}$.

Há mais de 50 anos o declínio da resposta vestibular por estimulação repetitiva foi observada por vários autores. Foi descrito por Dodge ${ }^{(19)}$, primeiramente observando-se pilotos e depois por Macbe ${ }^{(20)}$ em relação aos patinadores ${ }^{(19,20)}$.

Boussens \& Vorsin ${ }^{(21)}$, desenvolveram um trabalho sobre as vantagens da prática de exercícios para pacientes com diversos tipos de tonturas que não haviam apresentado melhora com medicamentos.

A descrição das bases fisiológicas dos exercícios por meio de um trabalho, foi realizada por Dix ${ }^{(22)}$, onde ela relatou a necessidade de haver igualdade na recepção 
sensorial vestibular para que ocorresse a interpretação correta pelo sistema nervoso central na manutenção do equilíbrio estático e dinâmico.

Um trabalho baseado essencialmente na repetição dos movimentos que provocavam tontura, mantendo a posição desencadeadora até a remissão da tontura (habituação) foi desenvolvido por Norré \& De Weerdt ${ }^{(23)}$ e por Brandt \&Daroff ${ }^{(24)}$.

Estes achados de Brandt \& Daroff ${ }^{(24)}$ motivaram o desenvolvimento de manobras posicionais ${ }^{(25,26,27)}$. Essas manobras baseiam-se na configuração anatômica do canal semicircular posterior e no movimento de cabeça em três diferentes posições com o objetivo de reposicionamento dos debris de otocônias patologicamente livres. Esses exercícios são indicados apenas para os casos de Vertigem Postural Paroxística Benigna ${ }^{(28)}$.

A reabilitação vestibular é um programa de terapia física associada a um conjunto de medidas relacionadas à mudança de hábitos e esclarecimentos sobre os sintomas ${ }^{(29)}$.

A reabilitação vestibular tem se mostrado muito importante podendo ser uma efetiva estratégia no tratamento do paciente com desordem do equilíbrio corporal proporcionando melhora da qualidade de vida ${ }^{(30,31)}$.

A reabilitação vestibular é considerada por alguns autores ${ }^{(32,33,34)}$ como o método de terapia mais fisiológico, inócuo e coerente, sendo tão importante quanto o tratamento medicamentoso ou cirúrgico.

Segundo Amá \& Oliveira ${ }^{(35)}$, a reabilitação vestibular é uma opção de tratamento de vestibulopatias que envolve estimulações visuais, proprioceptivas e vestibulares, com o intuito de manter o equilíbrio corporal dos pacientes com sintomas vertiginosos, seu propósito é recuperar a função global do sistema de 
equilíbrio independente da etiologia. Isto porque a compensação é esperada como resultado de uma ação do sistema nervoso central e não da solução da patologia periférica envolvida.

De acordo com Konnur ${ }^{(36)}$, a terapia de reabilitação vestibular pretende trabalhar o paciente vertiginoso aliviando os sintomas e aumentando seu limiar para a vertigem.

Para Ganança \& Ganança ${ }^{(37)}$, os principais objetivos da reabilitação vestibular é a promoção da estabilização visual e o aumento da interação vestíbulo- visual durante o movimento de cabeça; a promoção de uma melhor estabilidade estática e dinâmica nas situações de conflito sensorial e a diminuição da sensibilidade individual durante o movimento encefálico.

A Reabilitação vestibular tem como intuito reintegrar o indivíduo em seu meio, devolvendo-lhe a segurança e auxiliando-o na recuperação do equilíbrio ${ }^{(38)}$.

Existem mecanismos envolvidos na compensação vestibular, e de acordo com Caovilla et $a l .{ }^{(39)}$, uma lesão labiríntica perturba a integração central das informações sensoriais e provoca deslocamento dos olhos e do corpo para um dos lados.

A compensação vestibular é formada pelos mecanismos de restauração celular, adaptação, acomodação, substituição e habituação, de fundamental importância, uma vez que constituem a base dos exercícios utilizados na terapia ${ }^{(37)}$.

Adaptação: Fenômeno que ajuda um paciente com disfunção periférica persistente a voltar ao normal ou próximo do normal. É ela que ajuda o indivíduo a se manter ereto novamente ${ }^{(40)}$.

Acomodação: Mecanismo pelo qual o cerebelo inibe o labirinto sadio, e um mecanismo central em que o SNC aumenta os potenciais elétricos no núcleo lesado e 
promove a substituição sensorial do labirinto lesado por aferências visuais, proprioceptivas e comissurais $^{(41)}$.

Substituição: Mecanismo que troca a função vestibular perdida por outras estratégias sensório-motor, a fim de recuperar a estabilidade do campo visual e ao equilíbrio corporal suprindo a falha vestibular ${ }^{(18)}$.

Habituação: Redução de uma resposta sensorial a um mesmo estímulo repetido a intervalos regulares. É um processo de adaptação baseado na repetição de um estímulo ${ }^{(42)}$. 


\subsection{Vertigem Postural Paroxística Benigna (VPPB)}

A Vertigem Postural Paroxística Benigna (VPPB) é a mais comum das vestibulopatias periféricas, caracterizada por uma tontura de caráter rotatório à mudança de posição da cabeça ou por determinada posição do corpo. A VPPB foi descrita inicialmente por Bárány ${ }^{(43)}$ no começo deste século, mas foram Dix \& Hallpike $^{(44)}$ que descreveram suas principais características clínicas e a manobra provocadora da vertigem.

Segundo Paparella et $a l^{(45)}$ a VPPB é uma condição que pode aparecer isoladamente ou associar-se a outras patologias, normalmente desencadeando e/ou exacerbando uma crise vertiginosa. A VPPB caracteriza-se por episódios paroxísticos de vertigens súbitas e fugazes.

Em 1969, Schucknecht ${ }^{(46)}$ assinalou a presença de otólitos na cúpula do ducto coclear posterior, em autópsia de um paciente que havia sofrido trauma craniano.

A VPPB embora relatada em todas as idades, é mais comum em idosos e no sexo feminino, conforme relatam alguns autores ${ }^{(47,48,49,50,51)}$

As possíveis causas da vertigem postural paroxística benigna são numerosas e variam conforme o autor pesquisado.

Pereira \& Scaff ${ }^{(52)}$, citam vida sedentária, erros alimentares, causa iatrogênica (pós cirurgia geral e otológica) e ainda relatam que 50\% dos casos têm origem idiopática

Para Ganança et al. ${ }^{(53)}$, a VPPB pode ser precipitada por traumatismo craniano, disfunção hormonal ovariana, distúrbios metabólicos e/ou cardiovasculares, infeções, pós cirurgia geral ou otológica, ototoxidade, lues, otite 
média, insuficiência vertebrobasilar, doenças psíquicas, envelhecimento. Pode também originar-se de outras doenças labirínticas como, por exemplo, doença de Ménière, neurite vestibular, labirintopatias metabólicas ou vasculares.

Hain $^{(16)}$ relata que a etiologia mais comum da VPPB em idosos é a degeneração do sistema vestibular.

Segundo Caovilla et al. ${ }^{(39)}$, a teoria da origem da VPPB é a de que cristais de carbonato de cálcio (otólitos) deslocam-se do utrículo para o canal semicircular posterior, superior ou lateral (ductolitíase) ou aderem à cúpula destes canais (cupulolitíase). Este deslocamento anormal de otólitos pode ser gerado por qualquer fator precipitante.

Ford Smith ${ }^{(54)}$ relata que Adler, em 1897, foi quem primeiro descreveu casos de vertigem postural, contudo a doença relatada por estes autores era acompanhada de perda auditiva grave.

Dix e Hallpike ${ }^{(44)}$ cunharam o termo VPPB.

A teoria da cupulolitíase foi descrita por Schucknecht ${ }^{(46)}$. Baseado nesta teoria, fragmentos de otocônias degenerativos da mácula do utrículo aderiam à cúpula do canal semicircular posterior, modificando as características de sensibilidade angular para um aumento de acelerarão linear em um sensor para aceleração linear, mediante a estimulação gravitacional ${ }^{(46,52,50)}$.

Ainda segundo Schucknecht ${ }^{(46)}$, em estudos realizados em ossos temporais de pessoas que tiveram VPPB, depósitos de substâncias basófilas foram encontradas na cúpula do canal semicircular posterior.

Hall et al. ${ }^{(55)}$ sugere a teoria da canaliculolitíase ou ductolitíase (figura 3), ou ainda canalitíase, onde partículas, em vez de se fixarem na cúpula, caem livremente 
para dentro do canal semicircular posterior e flutuam na endolinfa. É a forma mais comum de VPPB.

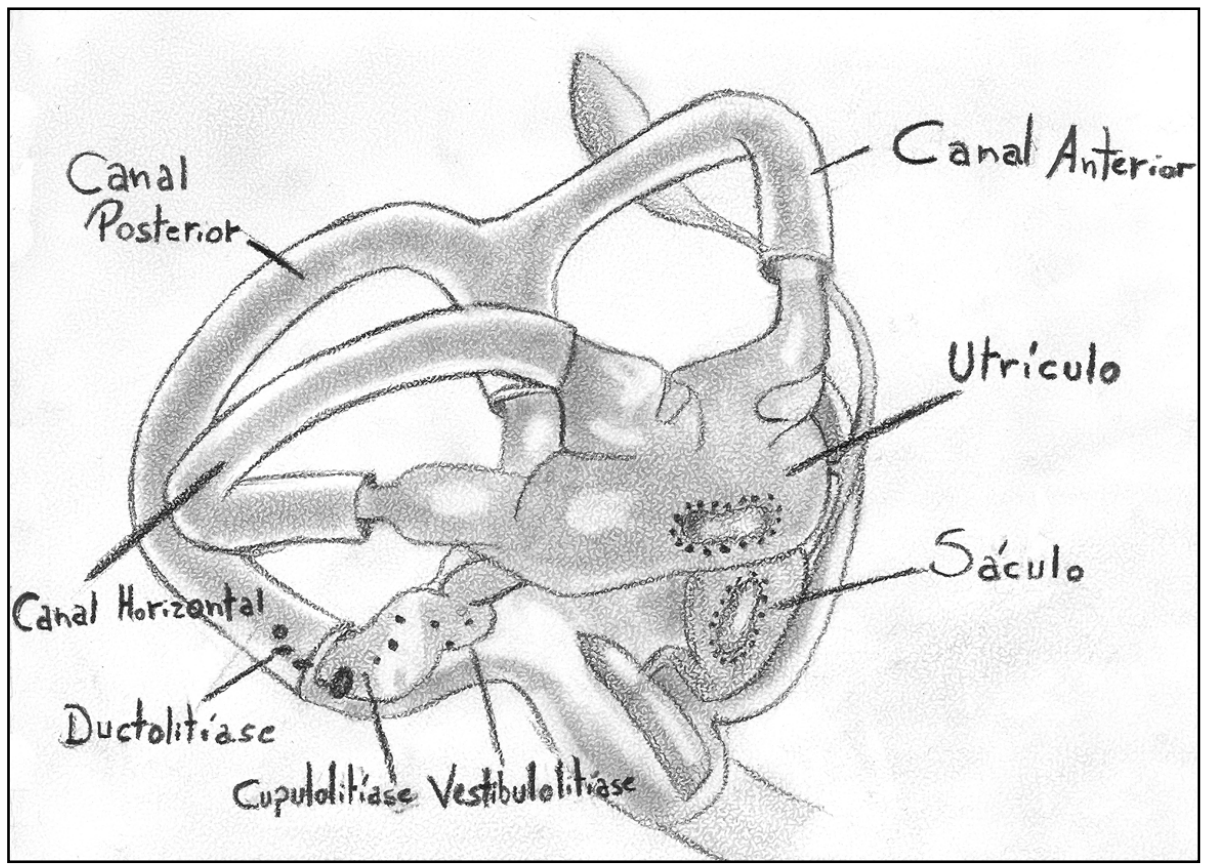

Figura 3- Substrato fisiopatológico da VPPB- Canalitíase - Cupulolitíase ${ }^{(16)}$

Existem algumas variantes a partir da duração e direção do nistagmo de posicionamento.

Substrato fisiopatológico da VPPB, de acordo com a direção e duração do nistagmo de posicionamento segundo alguns autores ${ }^{(49,51)}$ (quadro 1). 


\section{QUADRO 1 - SUBSTRATO FISIOPATOLÓGICO DO ACOMETIMENTO DOS CANAIS VERTICAIS $^{(49,51)}$}

\begin{tabular}{|c|c|}
\hline NISTAGMO DE POSICIONAMENTO & $\begin{array}{c}\text { SUBSTRATO } \\
\text { FISIOPATOLÓGICO }\end{array}$ \\
\hline MENOS DE UM MINUTO & DUCTOLITÍASE \\
\hline Vertical superior e rotatório anti- horário, com cabeça para a direita & Canal posterior direito \\
\hline Vertical superior e rotatório horário, com cabeça para a esquerda & Canal posterior esquerdo \\
\hline Vertical inferior e rotatório anti- horário, com cabeça para a direita & Canal superior direito \\
\hline Vertical inferior e rotatório horário, com cabeça para a esquerda & Canal superior esquerdo \\
\hline Horizontal geotrópico mais forte, com orelha direita para baixo & Canal lateral esquerdo \\
\hline Horizontal geotrópico mais forte, com orelha esquerda para baixo & Canal lateral direito \\
\hline MAIS DE UM MINUTO & CUPULOLITÍASE \\
\hline Vertical superior e rotatório anti- horário, com cabeça para a direita & Canal posterior direito \\
\hline Vertical superior e rotatório horário, com cabeça para a esquerda & Canal posterior esquerdo \\
\hline Vertical inferior e rotatório anti- horário, com cabeça para a direita & Canal superior direito \\
\hline Vertical inferior e rotatório horário, com cabeça para a esquerda & Canal superior esquerdo \\
\hline Horizontal geotrópico mais forte, com orelha direita para baixo & Canal lateral esquerdo \\
\hline Horizontal geotrópico mais forte, com orelha esquerda para bai & Canal lateral direito \\
\hline
\end{tabular}

Para Hain ${ }^{(16)}$, o diagnóstico do paciente com VPPB deve ser realizado baseado na história clínica do paciente, em achados no exame físico e nos resultados do teste auditivo e vestibular.

Para um diagnóstico mais preciso são utilizadas manobras provocativas da vertigem.

Duas diferentes manobras podem ser usadas para provocar a vertigem e o nistagmo para o diagnóstico da VPPB de canal posterior (figura 4 e 5). Uma vez que a observação da direção e da duração do nistagmo é essencial para o desenvolvimento de um plano de tratamento ${ }^{(50)}$. 


\section{Manobra ou Teste de Dix-Hallpike}

Também chamado de manobra de Bárány ou de Nylen- Bárány, este é o teste mais comumente usado para confirmar o diagnóstico de $\mathrm{VPPB}^{(50)}$.

O teste de Dix- Hallpike consiste em uma manobra provocativa das vertigens, pode eliciar o clássico nistagmo.

O paciente é colocado sentado no divã com a cabeça voltada $45^{\circ}$ para o lado a ser avaliado, posteriormente o paciente deverá ir para trás deitando bruscamente com a cabeça ficando pendente por, no mínimo, 20- 30 segundos e se observa a presença de nistagmo e/ou tontura. Paciente retorna, então, à posição sentada, mantendo a cabeça do mesmo lado e observa-se o nistagmo, quanto à duração e direção. O mesmo teste é realizado, também, do outro lado ${ }^{(26,47,56,37,50)}$.

Segundo Ganança \& Caovilla ${ }^{(47)}$, os possíveis resultados deste teste são: negativo, positivo objetivo e positivo subjetivo (quadro 2).

QUADRO 2 - POSSÍVEIS RESULTADOS DO TESTE DIX HALLPIKE

\begin{tabular}{|l|l|}
\hline RESULTADO & PRESENÇA OU AUSENCIA DE NISTAGMO E/ OU VERTIGEM \\
\hline Positivo objetivo & presença de nistagmo associado à vertigem \\
Positivo subjetivo & presença de vertigem \\
Negativo & ausência de nistagmo e vertigem \\
\hline
\end{tabular}




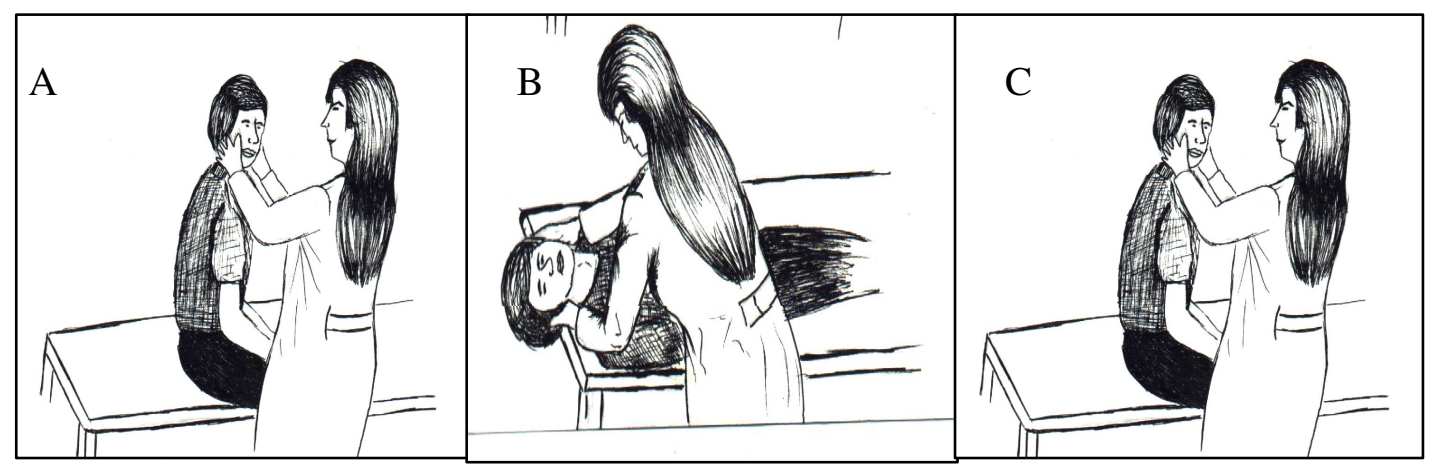

Figura 4 - Demonstração da Manobra de Dix- Hallpike

\section{Manobra ou Exercício de Brandt-Daroff}

Segundo Herdman \& Tusa ${ }^{(50)}$, este é denominado teste deitado de lado, e neste teste, o paciente muda da posição sentada em uma maca rapidamente para a posição decúbito lateral que provoca vertigem, mantendo a região occipital da cabeça sobre a maca formando um angulo de $45^{\circ}$ para cima.

A manobra de Brandt- Daroff é descrito por Ganança et al. ${ }^{(14)}$ e Ganança et $a l{ }^{(53)}$, como um método diagnóstico para confirmação da VPPB e também como método terapêutico da VPPB em pacientes não totalmente assintomáticos.

Este exercício será descrito com riqueza de detalhes no item tratamento. 


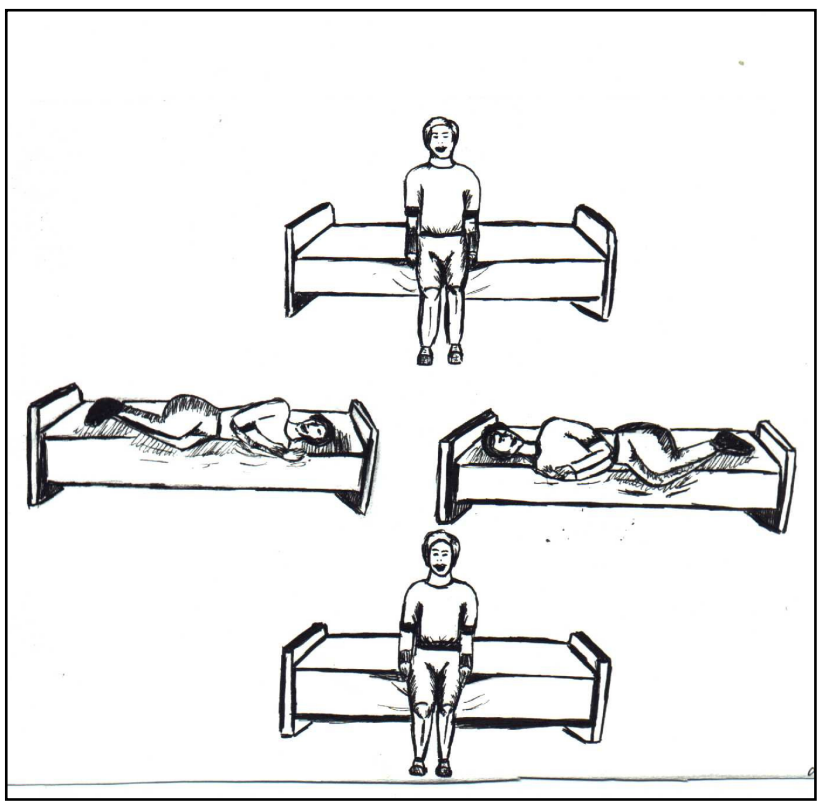

Figura 5 - Demonstração do exercício de Brandt- Daroff

\subsubsection{Tratamento}

Segundo Amá \& Oliveira $^{(57)}$, o tratamento da VPPB inclui:
a- Anamnese (ANEXO C)
b- Reforço quanto à dieta e recomendações quanto à mudança de hábito;
c- Manobras de reposicionamento
c- Orientações Pós Manobra de Reposicionamento e Liberação
d- Monitorização do tratamento

\section{a- Anamnese}

Neste estudo foi utilizada a anamnese (ANEXO C) usada no Setor de Fonoaudiologia do Hospital das Clínicas da Faculdade de Medicina de Ribeirão Preto- USP, elaborada por André ${ }^{(58)}$. 
Nesta primeira etapa do tratamento foram fornecidas informações ao paciente e familiares quanto à anatomia e fisiologia do sistema vestibular.

\section{b- Reforço Quanto à Dieta e Recomendações Quanto à Mudança de Hábito}

A dieta e os hábitos de um paciente com tontura devem ser baseados nas seguintes orientações ${ }^{(59,61)}$.

A- Fracionar a alimentação ao longo do dia, não permanecendo tempo superior a 3 horas no período diurno sem a ingestão de alimento, pois parte importante do nosso gasto energético vem da própria metabolização dos alimentos. O organismo exige receber nutrientes em intervalos regulares, pois, assim é possível manter uma absorção constante e ideal do carboidrato de absorção lenta, que é ingerido em cada refeição. O objetivo de uma dieta fracionada é evitar episódios de hipoglicemia.

B- Evitar carboidratos de rápida absorção, pois a orelha interna possui intensa atividade metabólica, pouca reserva de energia armazenada e depende do suprimento constante de oxigênio e glicose sangüínea para sua atividade. Quando há excessiva concentração de insulina no sangue, ocorre retenção de sódio na endolinfa, que expulsa o potássio e retém aumento de quantidade de água no espaço endolinfático, causando o bloqueio da bomba de sódio- potássio. Com a lesão ou degeneração das estruturas do ouvido interno, o controle independente pode ser perdido e o volume e a concentração do líquido da orelha interna flutuam, influenciados pelas mudanças nos líquidos produzidas pela ingestão de certas substâncias como o açúcar. Esta flutuação afeta a orelha interna e causa 
hydrops endolinfático: pressão e plenitude auricular, zumbido, tonturas e desequilíbrio. Nos casos de VPPB decorrente de distúrbios metabólicos ligados ao açúcar, o ideal é a eliminação deste alimento ou substituí-lo pelo adoçante.

C- Evitar o fumo, pois a nicotina presente nos cigarros produz à vasoconstricção, o que conduz a uma diminuição do fluxo sangüíneo para a orelha interna, fazendo os sintomas cocleovestibulares piorarem.

D- Limitar ou eliminar a ingestão de álcool, pois pode afetar diretamente o ouvido interno, mudando o volume e a concentração dos seus líquidos, causando ou aumentando os sintomas cocleovestibulares.

E- Evitar líquidos e alimentos que contenham cafeína , uma vez que a mesma é um agente diurético que leva à perda excessiva de líquidos pela urina e possui propriedades que pioram o zumbido e a vertigem.

F- Praticar atividade física. A prática de exercícios físicos melhora o metabolismo geral e acelera a compensação vestibular.

\section{c- Manobras de Reposicionamento}

Segundo Ruckenstein ${ }^{(61)}$, a reabilitação vestibular é considerada o tratamento de primeira escolha na VPPB.

É considerada, atualmente, um segmento fundamental dentro da terapia otoneurológica integrada e segundo Epley ${ }^{(26)}$; Aburto et al. ${ }^{(62)}$; Serafini et al. ${ }^{(63)}$, por meio das manobras de RV, a cura pode ser conseguida para cada canal semicircular envolvido em $87 \%$ a $100 \%$ dos casos. 
Porém em casos raros, segundo Lavinsky ${ }^{(65)}$; Brandt \& Daroff ${ }^{(24)}$, onde a melhora clínica não foi obtida após tratamento adequado, há indicação de procedimento cirúrgico.

De acordo com Lavinsky ${ }^{(64)}$, a VPPB é uma doença autolimitada na grande maioria dos pacientes, porém a Neurectomia do nervo singular tem sido recomendada para pacientes que estejam incapacitados pela VPPB por um ano, não obstante o tratamento médico e fisioterápico.

Segundo Gacek $^{(65)}$, são extremamente raros os casos que dependem dessa cirurgia, o que dificulta a aquisição de experiência relevante.

Para Herdman \& Tusa ${ }^{(50)}$, o sucesso do tratamento depende da identificação de qual canal está envolvido e se o detrito está flutuando livremente (ductolitíase) ou se aderiu à cúpula (cupulolitíase). Existem três tratamentos básicos para a VPPB com suas indicações de uso: reposição canalítica, exercícios de liberação e exercícios de habituação de Brandt - Daroff.

\section{A-Tratamento de Reposicionamento Canalítico (Ductolitíase) dos Canais Anterior e Posterior}

Este tratamento é baseado na teoria da ductolitíase. Ele envolve uma única manobra, na qual o paciente altera a posição cefálica diversas vezes para movimentar os detritos.

A manobra de reposição canalítica (MRC), proposta por Epley, e suas modificações é bastante efetiva para liberar, por meio do deslocamento dos detritos, o canal afetado ${ }^{(67)}$. 
Pereira \& Scaff ${ }^{(52)}$, Ganança \& Ganança ${ }^{(37)}$, Herdman \& Tusa ${ }^{(50)}$, nomeiam esta manobra de TRC- tratamento de reposição canalítica enquanto Ganança \& Caovilla $^{(47)}$, Froehling et al. ${ }^{(56)}$, Maia et al. ${ }^{(67)}$, usam o termo manobra de Epley, na qual o paciente é primeiro colocado na posição em que o teste de Dix- Hallpike apresentou resultado positivo por 3 minutos. A cabeça do paciente é direcionada para o lado intacto e mantida por um período de 3 minutos, deve-se, então, solicitar que o paciente faça uma rotação do corpo e assuma a posição decúbito lateral, com a cabeça virada em $45^{\circ}$ para baixo. Mantendo a cabeça desviada na direção do lado intacto e inclinada para baixo, o paciente senta-se lentamente.

Durante a manobra, o paciente pode ter vertigem e nistagmo, mas é importante permanecer na posição desencadeadora, uma vez que os debris estão se movendo dentro dos canais semicirculares e voltando ao utrículo ${ }^{(50)}$.

Com a finalidade de manter os detritos no utrículo, o paciente recebe algumas orientações pós manobras que serão descritas detalhadamente no próximo item do tratamento.

Após a realização da manobra de Epley o paciente deve utilizar um colar cervical para reduzir a movimentação cefálica ${ }^{(15)}$. 


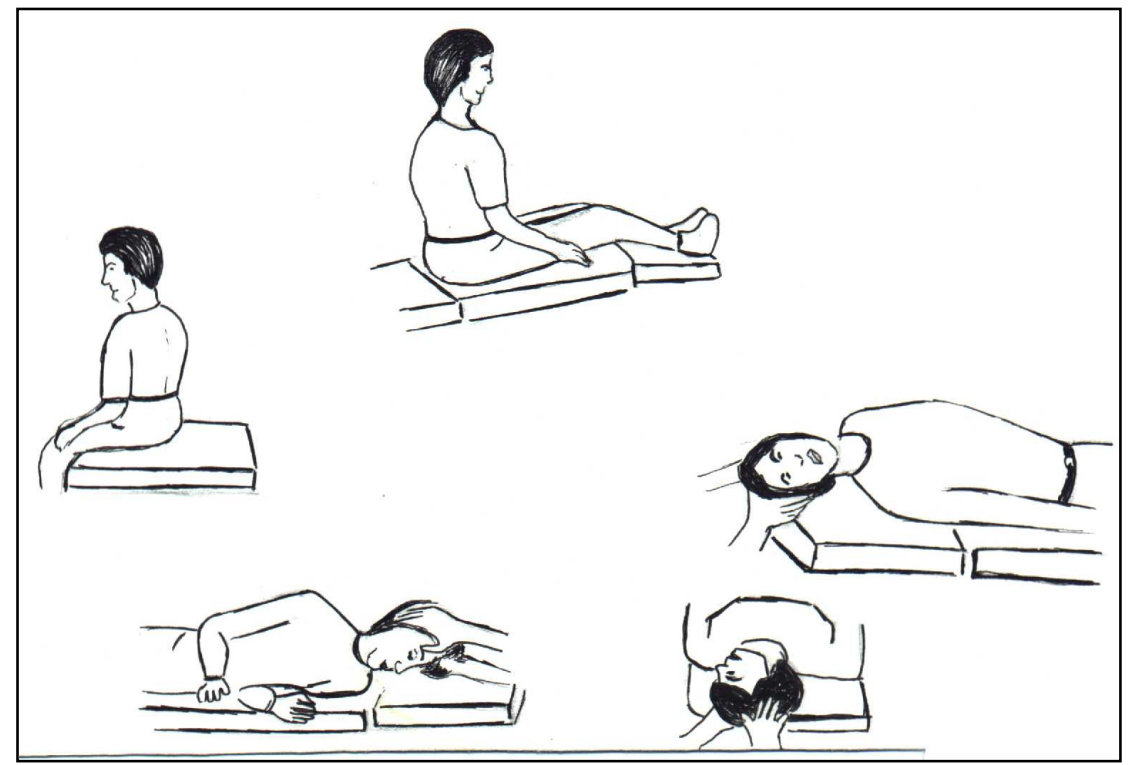

Figura 6 - Demonstração da Manobra de Epley

\section{B- EXERCÍCIOS DE HABITUAÇÃO OU MANOBRA DE BRANDT- DAROFF}

Para Guzmán et $a l .^{(68)}$, o exercício deve ser utilizado como complemento terapêutico para pacientes não totalmente assintomáticos após manobra de reposicionamento, sendo orientada sua realização em domicílio.

$\mathrm{Na}$ modificação proposta por estes mesmos autores, o exercício deve ser realizado com o paciente sentado na maca ou em sua cama, rapidamente vai de decúbito lateral do lado afetado para o lado não afetado também em decúbito lateral. A cabeça deve estar com uma inclinação de 45 graus para cima e ao sentar-se de frente deve manter o olhar fixo, voltando à posição inicial. Durante todas as posições o paciente deve manter o olhar fixo a sua frente e permanecer nesta posição por 10 segundos ou até que haja a remissão da vertigem. A posição desencadeadora da vertigem é mantida por período de 30 segundos ou até a extinção da vertigem, no 
caso da mesma ser desencadeada pelo exercício. Paciente, então, deve retornar à posição sentada, espera-se novamente o mesmo período e adota-se o decúbito lateral do lado não afetado, esperando o mesmo período e voltando à posição sentada. O exercício deve ser repetido a cada 3 horas até que o paciente fique assintomático por dois dias consecutivos.

Para Ganança \& Ganança ${ }^{(37)}$, o exercício deve ser realizado utilizando os mesmos procedimentos citados anteriormente, ou relata também a realização deste sem a parada no centro, indo do lado afetado diretamente para o lado não afetado. Para estes autores o exercício deve ser repetido de 5 a 10 vezes.

André(69), Hain ${ }^{(16)}$, propõem que o exercício deve seguir os mesmos procedimentos realizados por Ganança \& Ganança ${ }^{(37)}$ porém utilizam exclusivamente o exercício com a mudança direta da posição de decúbito lateral do lado afetado para o não afetado, sem a necessidade de manter-se por algum tempo nesta posição. André ${ }^{(69)}$ sugere que o exercício deve ser feito duas vezes ao dia em domicílio, em série de 10 exercícios consecutivos. Enquanto Hain ${ }^{(16)}$, sugere que o exercício deve ser realizado em 3 séries de 5 repetições, o que despenderia 10 minutos para sua execução (quadro 3).

QUADRO 3 - SUGESTÃO DE REALIZAÇÃO DO EXERCÍCIO DE BRANDTDAROFF $^{(15)}$.

\begin{tabular}{|l|l|l|}
\hline TEMPO & EXERCÍCIOS & DURAÇÃO \\
\hline MANH Ã & 5 REPETIÇÕES & 10 MINUTOS \\
TARDE & 5 REPETIÇÕES & 10 MINUTOS \\
NOITE & 5 REPETIÇÕES & 10 MINUTOS \\
\hline
\end{tabular}


De acordo com Herdman \& Tusa ${ }^{(50)}$, o exercício de Brandt- Daroff pode ser uma acertada opção para a VPPB, quando os canais posteriores estiverem acometidos bilateralmente.

\section{d- Orientações Pós Manobra de Reposicionamento e Liberação}

Após a realização das manobras o paciente deverá seguir as seguintes orientações, sugeridas por diversos autores.

1- Evitar a posição desencadeadora da vertigem durante uma semana;

2- Dormir semi sentado nas próximas 48 horas deixando a região cefálica fletida num ângulo de $45^{\circ}$ (Figura 7);

3- Fazer uso de um colar cervical por 48 horas a fim de imobilizar a região cervical impedindo movimentos cefálicos. O colar cervical pode ser confeccionado com atadura de algodão de $20 \mathrm{~cm}$ e malha tubular de $4 \mathrm{~cm}$;

4- Evitar movimentos cefálicos bruscos;

5- Após o período de 48 horas o paciente deve retomar as suas atividades de vida diária sem restrições quanto ao movimento ${ }^{(37,47,48,50,56,69)}$. 


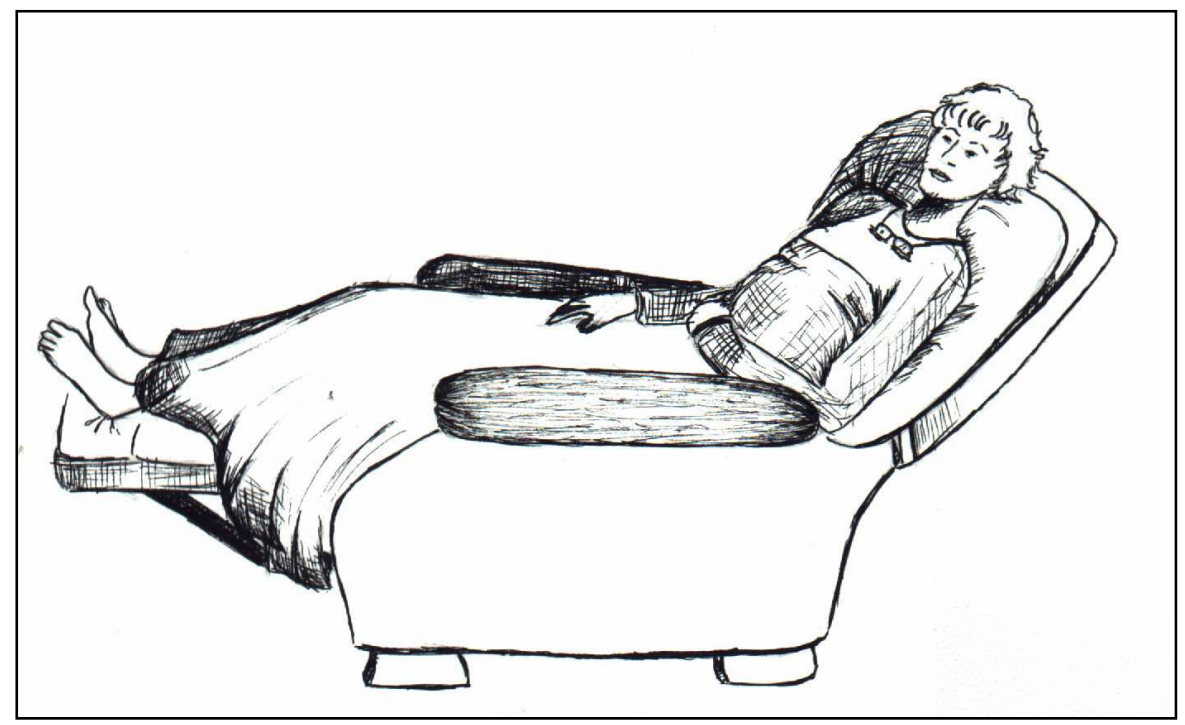

Figura 7- Demonstração da posição para dormir no período de 48 horas, após colocação do colar cervical

\section{e- Monitorização do Tratamento}

As manobras de monitorização são as mesmas utilizadas no diagnóstico da VPPB conforme descritas no item método diagnóstico. 


\subsection{OBJETIVOS}

\section{OBJETIVO GERAL}

Avaliar prospectivamente a Reabilitação Vestibular no tratamento da Vertigem Postural Paroxística Benigna acometimento do canal posterior e seu efeito na qualidade de vida em indivíduos idosos.

\section{OBJETIVOS ESPECÍFICOS}

- Caracterização dos idosos voluntários quanto à idade, gênero, lado acometido pela VPPB.

- Levantamento do tipo de manobra utilizada no tratamento da VPPB dos idosos voluntários.

- Levantamento do número de manobras de Epley necessárias no tratamento da VPPB dos idosos voluntários.

- Tempo de duração do tratamento da VPPB considerando o período da anamnese à alta.

- Comparação dos escores obtidos pelos idosos voluntários no DHI brasileiro pré e pós reabilitação vestibular.

- Avaliar se há correlação entre os aspectos físico, emocional, funcional e geral e idade dos idosos voluntários. 
- Avaliar se há a associação entre a idade do idosos voluntários e a diferença de escores dos aspectos físico, emocional, funcional e geral pré e pós reabilitação vestibular.

- Avaliar se há a associação entre o gênero dos idosos voluntários e a diferença de escores físico, emocional, funcional e geral pré e pós reabilitação vestibular. 


$$
\mathbf{C}_{\text {mansitia }} \cdot \mathbf{M}_{\text {Motate }}
$$




\section{CASUÍSTICA E MÉTODOS}

\subsection{Considerações Éticas}

O plano do presente estudo foi submetido à Comissão de Normas Éticas e Regulamentares do Hospital das Clínicas da Faculdade de Medicina de Ribeirão Preto da Universidade de São Paulo (HCFMRP-USP), que o examinou e aprovou, no processo de número 4873/2001 (ANEXO A)

Posteriormente todos os voluntários foram informados sobre todos os detalhes do estudo e manifestaram o seu consentimento por escrito.(ANEXO B)

\subsection{Casuística}

Participaram do presente estudo, 23 pacientes voluntários, com idade superior a 60 anos, de ambos os sexos, oriundos do Ambulatório de Otoneurologia do Hospital das Clínicas da Faculdade de Medicina de Ribeirão Preto da Universidade de São Paulo.

Todos os pacientes que fizeram parte deste estudo apresentaram diagnóstico médico de Vertigem Postural Paroxística Benigna de canal posterior firmado pelo médico otorrinolaringologista e concordaram em participar deste estudo livremente. 


\section{CRITÉRIOS DE EXCLUSÃO}

- Uso de medicações que possam inibir ou excitar a função vestibular

- Demais vestibulopatias

- Pacientes com idade inferior a 60 anos

- $\quad$ VPPB de canal horizontal e superior

- Pacientes com história pregressa de doença cervical grave

- Pacientes com história pregressa de descolamento de retina

\subsection{Coleta de Dados}

Todos os pacientes passaram por uma mesma seqüência de protocolo para coleta dos dados:

- Consulta prévia com Otorrinolaringologista, diagnóstico médico de VPPB de canal posterior

- Encaminhamento para Reabilitação Vestibular

- Termo de consentimento livre e esclarecido (ANEXO B)

- Anamnese fonoaudiológica (ANEXO C)

- Avaliação da vertigem por meio de questionário pré- terapia (ANEXO D)

- Reabilitação vestibular realizada por meio de manobras de reposicionamento para canal posterior realizada por fonoaudióloga

- Avaliação da vertigem por meio de questionário pós-terapia (ANEXO D) 
Todos os procedimentos foram realizados no setor de fonoaudiologia do Hospital das Clínicas da Faculdade de Medicina de Ribeirão Preto- USP

A anamnese utilizada abrangeu questões sobre as características dos episódios de tontura; aspectos emocionais e limitação de vida desenvolvida à partir da tontura; sintomas associados à tontura; fatores desencadeantes ou exacerbantes da tontura; manifestações auditivas; hábito e dieta realizada e antecedentes familiares. (ANEXO C).

Posteriormente foram feitas questões sobre o aspectos físicos, emocionais e funcionais relacionados as manifestações clínicas da VPPB, utilizando para isso o questionário de handicap para tontura (DHI brasileiro) (ANEXO D), onde o paciente teve que responder às questões com uma das seguintes respostas: sempre (4), às vezes (2) e nunca (0). Este questionário foi utilizado pré e pós Reabilitação Vestibular.

Jacobson \& Newman, ${ }^{(70)}$ desenvolveram o DHI brasileiro, e o mesmo foi traduzido e adaptado cuturalmente por Castro et al. ${ }^{(71)}$ (ANEXO D), no qual o paciente respondeu às questões com uma das seguintes respostas: sempre (4), às vezes (2) e nunca (0) para verificação se houve ou não melhora referente aos aspectos pesquisados nas questões sobre a sintomatologia pós- realização da terapia.

Logo após, o paciente foi submetido às manobras de reabilitação vestibular específicas para o tratamento da VPPB de canal posterior levando em consideração o substrato fisiopatológico das mesmas.

Para realização das manobras o método utilizado foi baseado nos autores Ganança \& Ganança ${ }^{(49)}$, Froehling et al. ${ }^{(56)}$, Maia et al. ${ }^{(70)}$. 
Para monitorização do tratamento a manobra selecionada foi o Teste de DixHallpike ${ }^{(37,47,50,56)}$. Como manobra de tratamento para reposicionamento canalítico foi feita a escolha pela manobra de Epley ${ }^{(37,47,50,67)}$.

Como complemento terapêutico para casos não totalmente assintomáticos foi utilizado o exercício de Brandt- Daroff ${ }^{(16)}$.

Foi utilizada uma seqüência padronizada de atendimento dos pacientes após a primeira manobra de Epley conforme protocolo modificado por André ${ }^{(69)}$ e Mantello et al. ${ }^{(72)}$ (figura 8). 


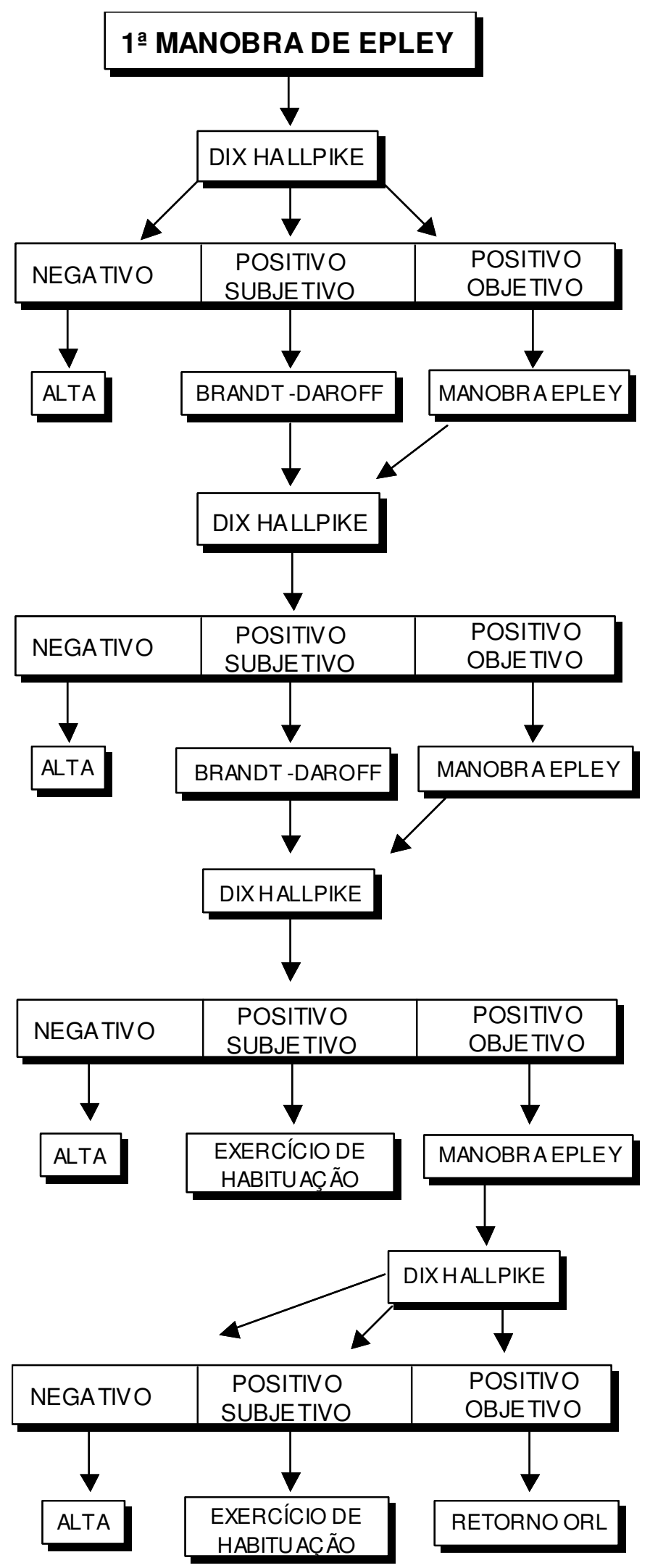

Figura 8: Fluxograma de atendimento da VPPB ${ }^{(72,74)}$ 
Após uma semana, o paciente retornou e foi realizado o teste de DixHallpike com o objetivo de avaliar o tratamento realizado, uma vez que o canal acometido foi o posterior em todos os casos. Nos casos com Dix Hallpike negativo, o paciente recebeu alta do tratamento. Nos casos positivo subjetivo, com tontura relatada de pouca intensidade, o paciente foi orientado a realizar o exercício de Brandt Daroff em domicílio, 3 vezes ao dia, 10 vezes cada exercício, iniciando do lado afetado. Nos casos positivo objetivo nova manobra de Epley foi realizada e novo retorno agendado para a semana posterior.

No retorno, novamente, utilizou-se a manobra de Dix- Hallpike para reavaliar o tratamento, caso negativo: alta da reabilitação vestibular. Na reavaliação, nos casos positivo subjetivo com tonturas leves: orientação ao paciente quanto à realização do exercício de Brandt- Daroff em domicílio, 3 vezes ao dia, 10 vezes cada exercício, iniciando do lado afetado. Caso na reavaliação paciente apresentasse Dix Hallpike com resultado positivo objetivo, repetiu-se a manobra de Epley e novo retorno foi agendado para a próxima semana. Novamente realizou-se o Dix Hallpike, e nos casos negativos, alta. Nos casos positivo subjetivo, exercícios de habituação; nos casos positivo objetivo, repetiu-se a manobra de Epley e retornou em uma semana para nova reavaliação por meio do teste de Dix Hallpike sendo que, nos casos negativo, é dado alta ao paciente e, nos casos positivo subjetivo, estimulou-se com exercícios vestibulares o reflexo vestíbulo-ocular, nos casos positivo objetivo reencaminhou-se o paciente para otorrinolaringologista para discussão de nova conduta terapêutica.

Após cada realização da manobra de Epley, orientações pós manobras foram dadas aos pacientes, assim como a colocação de um colar cervical foi utilizada, 
sendo que os pacientes permaneceram com o mesmo, por um período de 48 horas após a manobra. O colar cervical foi confeccionado pela própria fonoaudióloga, com malha tubular de $4 \mathrm{~cm}$ de largura Cremer $^{\circledR}$ e 3 ataduras de algodão ortopédico com 20 cm de largura cada, também, Cremer ${ }^{\circledR}$.

Outras orientações pós manobra foram dadas aos pacientes: dormir por um período similar ao que iria ficar com o colar cervical em cabeceira à 45 graus (Figura 7) e decúbito dorsal e não freqüentar dentistas e cabeleireiro por período de 48 horas. Após as 48 horas retornar às atividades habituais observando a sua sintomatologia para que pudesse relatar à fonoaudióloga no retorno.

Os pacientes receberam orientações quanto ao reforço da dieta, que enfocou questões como distribuir as refeições ao longo do dia; não permanecer mais que três horas sem a ingestão de alimentos; evitar o consumo de carboidratos de rápida absorção; evitar alimentos e bebidas com cafeína e quanto às mudanças de hábitos enfatizou-se a restrição do consumo de bebidas alcóolicas, fumo, situações estressantes e repouso prolongado de acordo com a necessidade individual observada na anamnese.

Na sessão, na qual, o paciente recebeu alta, foram realizadas, novamente, questões sobre os aspectos físicos, emocionais e funcionais relacionados à manifestações clínicas da VPPB (Dizziness Handicap Inventory brasileiro).

Com o objetivo de analisar os dados posteriormente, foi realizado um relatório que constava dos itens do atendimento em cada sessão. 


\subsection{ANÁLISE ESTATÍSTICA}

Todos os dados colhidos por meio de uma pesquisa experimental, qualiquantitativa, com a finalidade terapêutica, foram analisados e tabelados e apresentados no próximo capítulo.

Para análise estatística dos dados foi utilizado o programa de computador Graph Pad .

Para a verificação do predomínio da VPPB em relação ao gênero e lado acometido foi utilizado o teste de Qui-quadrado .

O teste de Wilcoxon foi utilizado para analisar os dados de duas amostras dependentes, pareadas e devido os dados serem não paramétricos. Este teste foi utilizado para analisar os valores de escores dos aspectos físicos, emocional, funcional, geral dos voluntários pré e pós Reabilitação Vestibular.

O teste exato de Fisher foi utilizado para analisar a correlação entre a diferença pré e pós reabilitação vestibular dos aspectos físico, emocional, funcional, geral e o gênero.

Com o intuito de verificar estatisticamente a associação dos aspectos físico, emocional, funcional e geral com a idade dos voluntários foi utilizado o teste de coeficiente de correlação Ordinal de Spearman.

Foram considerados significativos valores de $\mathrm{p}<0,05$. 


\section{Desultados}




\section{RESULTADOS}

Todos os voluntários estudados apresentaram VPPB com comprometimento de ductolitíase diagnóstico definido pelo médico otorrinolaringologista (quadro 4). Observou-se que a idade da população estudada variou de 60 à 91anos de idade (gráfico 1) com média de 70,69 e desvio padrão de 9,24.

Quanto ao gênero, da amostra total dos pacientes, 17 (73,9\%) eram do gênero feminino e $6(26,1) \%$ masculino (gráfico 2). 


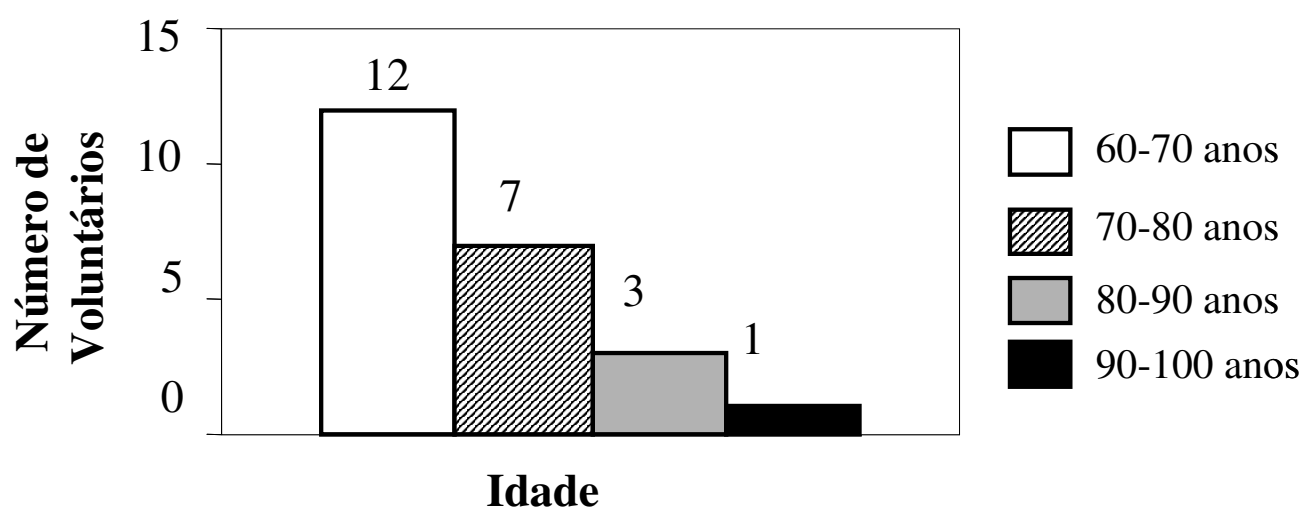

Gráfico 1 Representação gráfica da distribuição dos indivíduos quanto à idade

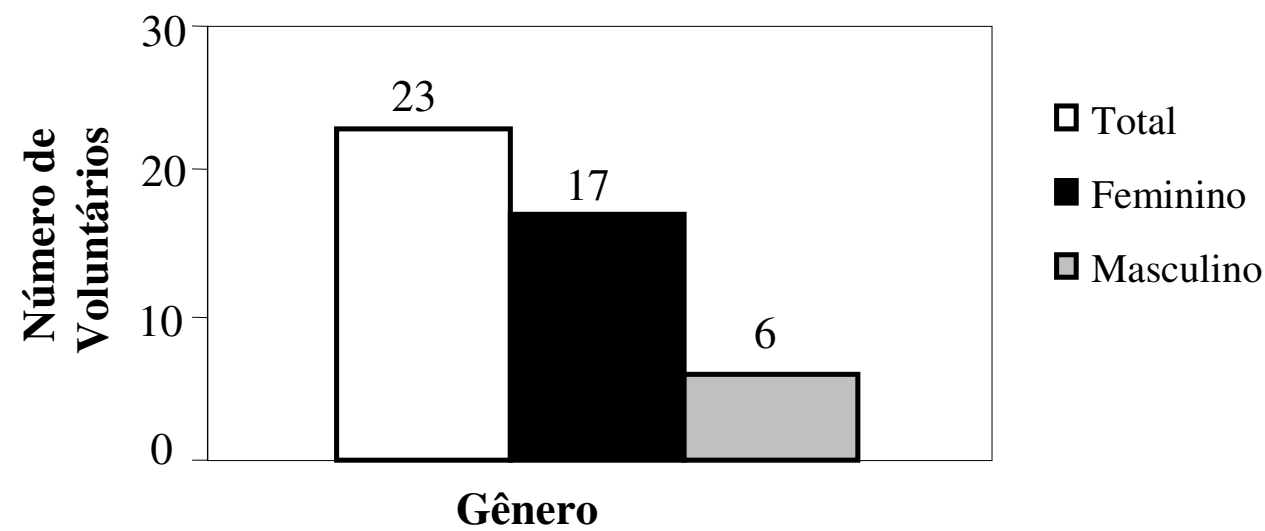

Gráfico 2- Representação gráfica da Distribuição dos indivíduos quanto ao gênero masculino e feminino 
Quadro 4- DESCRIÇÃO DOS 23 VOLUNTÁRIOS QUANTO A IDADE, SEXO, DIAGNÓSTICO, CANAL SEMICIRCULAR ACOMETIDO E LADO ACOMETIDO

\begin{tabular}{|l|c|c|l|l|}
\hline VOLUNTÁRIOS & $\begin{array}{c}\text { IDADE } \\
\text { (anos) }\end{array}$ & Gênero & DIAGNÓSTICO & LADO ACOMETIDO \\
\hline A.A.S. & 73 & $\mathrm{~F}$ & DUCTOLITIASE & ESQUERDO \\
A.B.L.V. & 91 & $\mathrm{~F}$ & DUCTOLITIASE & DIREITO \\
A.B.S. & 89 & $\mathrm{M}$ & DUCTOLITIASE & ESQUERDO \\
A.F.Z. & 73 & $\mathrm{~F}$ & DUCTOLITIASE & ESQUERDO \\
A.M. & 87 & $\mathrm{M}$ & DUCTOLITIASE & DIREITO \\
A.M.B. & 72 & $\mathrm{~F}$ & DUCTOLITIASE & DIREITO \\
B.G. & 75 & $\mathrm{M}$ & DUCTOLITIASE & DIREITO \\
C.A.S. & 64 & $\mathrm{~F}$ & DUCTOLITIASE & ESQUERDO \\
C.C.A. & 62 & $\mathrm{~F}$ & DUCTOLITIASE & ESQUERDO \\
C.M.M.N. & 67 & $\mathrm{~F}$ & DUCTOLITIASE & ESQUERDO \\
E.A.C.S. & 60 & $\mathrm{~F}$ & DUCTOLITIASE & ESQUERDO \\
E.C.S. & 63 & $\mathrm{~F}$ & DUCTOLITIASE & DIREITO \\
E.M.C. & 70 & $\mathrm{~F}$ & DUCTOLITIASE & ESQUERDO \\
F.B. & 85 & $\mathrm{~F}$ & DUCTOLITIASE & DIREITO \\
J.C.S. & 62 & $\mathrm{M}$ & DUCTOLITIASE & ESQUERDO \\
J.S. & 72 & $\mathrm{~F}$ & DUCTOLITIASE & ESQUERDO \\
J.V.G. & 62 & $\mathrm{M}$ & DUCTOLITIASE & DIREITO \\
M.I.B.R. & 62 & $\mathrm{M}$ & DUCTOLITIASE & ESQUERDO \\
M.I.D. & 64 & $\mathrm{~F}$ & DUCTOLITIASE & ESQUERDO \\
M.J.S.B. & 72 & $\mathrm{~F}$ & DUCTOLITIASE & DIREITO \\
M.M.P. & 65 & $\mathrm{~F}$ & DUCTOLITIASE & DIREITO \\
M.V.F. & 68 & $\mathrm{~F}$ & DUCTOLITIASE & DIREITO \\
T.M.D.S. & 68 & $\mathrm{~F}$ & DUCTOLITIASE & ESQUERDO \\
\hline
\end{tabular}

Dos 23 voluntários estudados, $16(69,58 \%)$, apresentaram acometimento da VPPB à esquerda, 7 (30,42 \%) voluntários o acometimento foi à direita (gráfico 3). Em três voluntários, do lado esquerdo houve a presença de nistagmo posicional e do lado direito houve relato de vertigem sem a presença de nistagmo simultaneamente. 


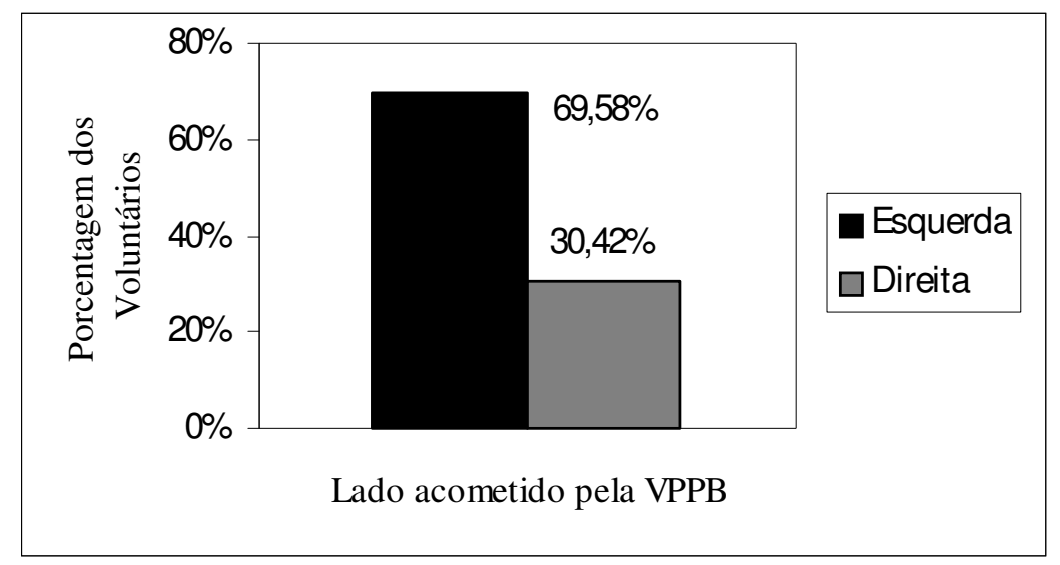

Gráfico 3: Representação gráfica do lado acometido pela VPPB nos voluntários estudados.

Dos 23 voluntários estudados, 17 (73,92\%) foram tratados com a aplicação da manobra de Epley; 6 (26,09\%) voluntários receberam a associação da manobra de Epley com o exercício de Brandt- Daroff (gráfico 4).

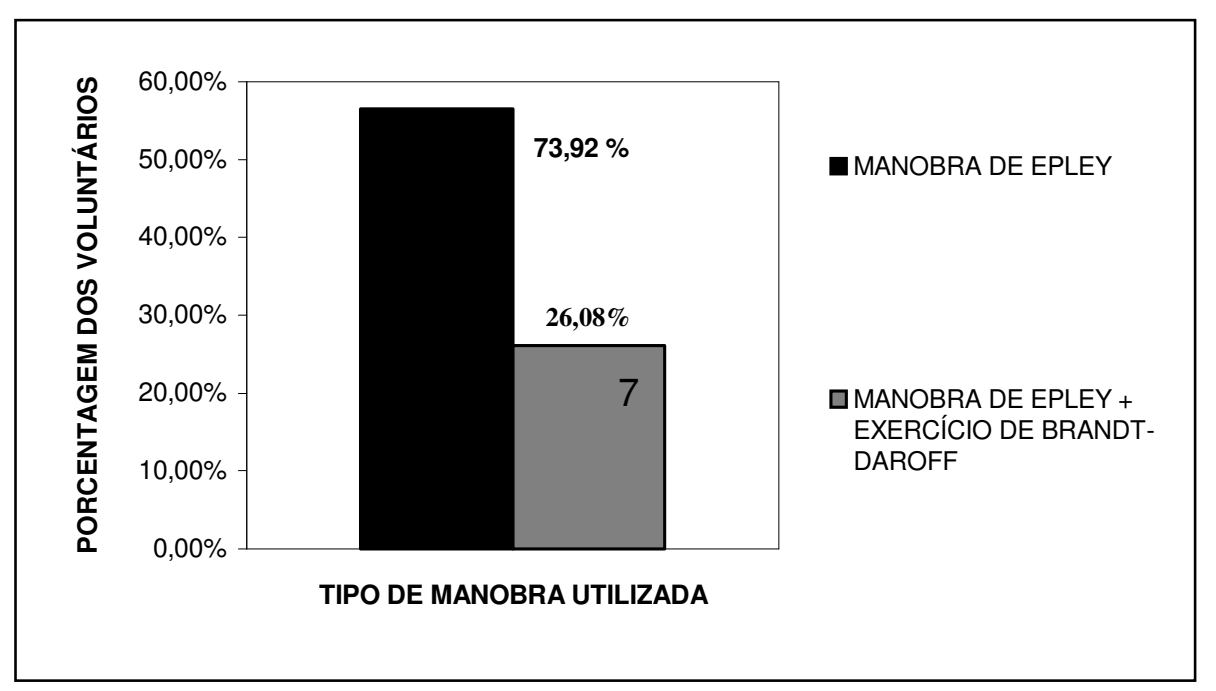

Gráfico 4- Descrição do tipo de manobra realizada no tratamento da VPPB dos 23 voluntários 
Dos voluntários submetidos somente a manobra de Epley como tratamento, em $17(73,91 \%)$ foi realizada uma única manobra, em 4 (17,39\%) foram eles submetidos a 2 manobras e $2(8,70 \%)$ dos voluntários foram submetidos a três. As manobras foram realizadas em sessões distintas (gráfico 5).

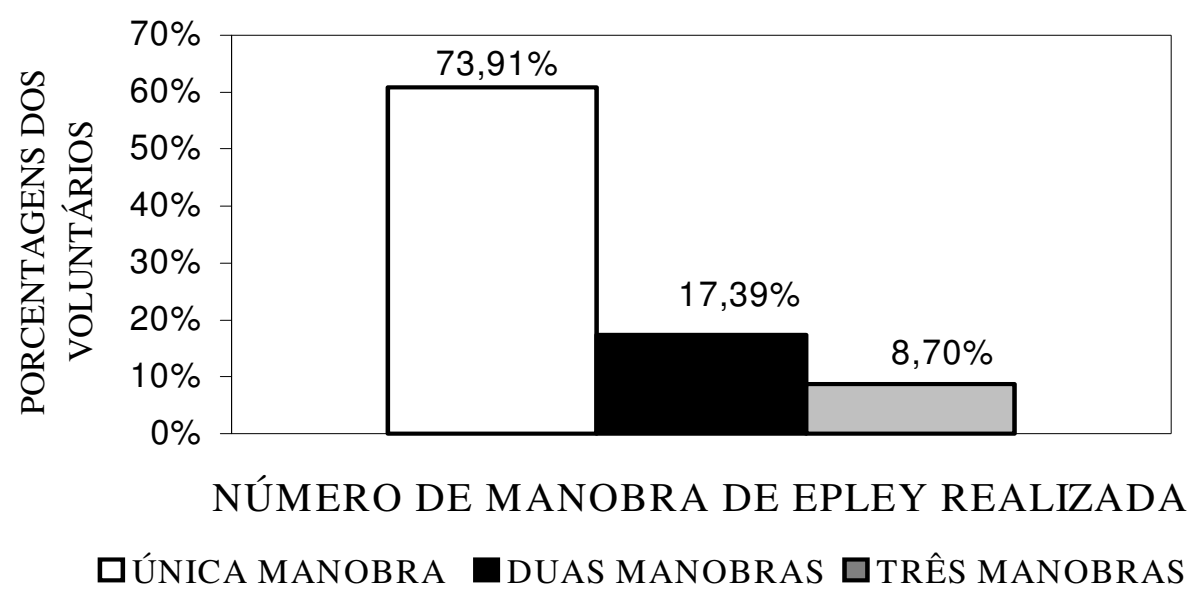

Gráfico 5 - Número de manobras de Epley realizadas no tratamento da VPPB dos 23 voluntários

A reabilitação vestibular variou quanto ao tempo de atendimento de 2 a 6 semanas, sendo que $8(34,78 \%)$ dos voluntários necessitaram de 2 semanas, 7 $(30,43 \%)$ passaram por 3 semanas , $4(17,39 \%)$ realizaram 4 semanas de atendimento, $3(13,05 \%)$ passaram por 5 semanas e $1(4,35 \%)$ restantes, a duração da terapia foi de 6 semanas (gráfico 6).

Dos 23 voluntários tratados, 100\% tornaram-se assintomáticos com a aplicação do tratamento proposto. 


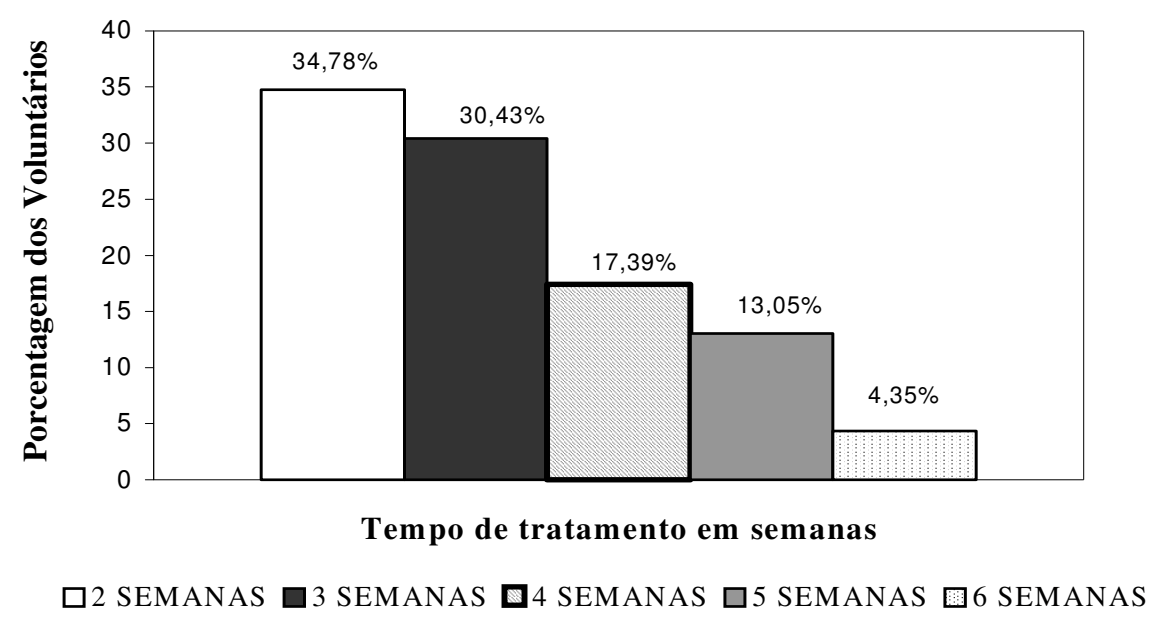

Gráfico 6 -Tempo de duração do tratamento da VPPB da anamnese à alta em semanas

A descrição dos 23 voluntários quanto aos escores observados no DHI brasileiro Pré e Pós RV quanto aos aspectos físicos, emocionais, funcionais e gerais denotam melhora em todos os aspectos pesquisado (Quadro 5). 
QUADRO 5- DESCRIÇÃO DOS 23 VOLUNTÁRIOS QUANTO AOS ESCORES DO ASPECTO FÍSICO, EMOCIONAL, FUNCIONAL E GERAL DO DHI BRASILEIRO PRÉ E PÓS RV

\begin{tabular}{|l|c|c|c|c|c|c|c|c|}
\hline Voluntários & \multicolumn{4}{|c|}{$\begin{array}{c}\text { DHI brasileiro } \\
\text { Pré RV }\end{array}$} & \multicolumn{5}{c|}{$\begin{array}{c}\text { DHI brasileiro } \\
\text { Pós RV }\end{array}$} \\
\hline & Físico & Emocional & funcional & geral & Físico & Emocional & funcional & geral \\
\hline EACS & 20 & 18 & 28 & 66 & 0 & 0 & 0 & 0 \\
\hline JCS & 26 & 36 & 30 & 92 & 2 & 12 & 10 & 24 \\
\hline ABS & 16 & 30 & 22 & 68 & 0 & 2 & 2 & 4 \\
\hline JVG & 22 & 6 & 14 & 42 & 2 & 0 & 6 & 8 \\
\hline BG & 24 & 16 & 32 & 72 & 4 & 6 & 10 & 20 \\
\hline MJSB & 24 & 14 & 14 & 52 & 0 & 0 & 2 & 2 \\
\hline JS & 12 & 8 & 16 & 36 & 0 & 2 & 0 & 2 \\
\hline FB & 16 & 2 & 16 & 34 & 0 & 0 & 6 & 6 \\
\hline MIBR & 20 & 12 & 18 & 50 & 2 & 8 & 4 & 14 \\
\hline AM & 22 & 24 & 22 & 68 & 2 & 4 & 2 & 8 \\
\hline ABLV & 10 & 22 & 20 & 52 & 0 & 12 & 6 & 18 \\
\hline AFZ & 18 & 26 & 26 & 70 & 4 & 8 & 8 & 20 \\
\hline MMP & 24 & 24 & 28 & 76 & 0 & 12 & 10 & 22 \\
\hline MVF & 18 & 8 & 14 & 40 & 0 & 4 & 2 & 6 \\
\hline EMC & 22 & 30 & 20 & 72 & 0 & 6 & 4 & 10 \\
\hline TMDS & 20 & 6 & 14 & 40 & 0 & 2 & 2 & 4 \\
\hline MID & 20 & 18 & 22 & 60 & 0 & 8 & 6 & 14 \\
\hline CMMN & 28 & 32 & 32 & 88 & 2 & 10 & 12 & 24 \\
\hline AMB & 24 & 24 & 22 & 70 & 0 & 8 & 6 & 14 \\
\hline CAS & 22 & 22 & 26 & 70 & 2 & 6 & 8 & 16 \\
\hline AAS & 22 & 18 & 20 & 60 & 2 & 4 & 2 & 8 \\
\hline CCA & 28 & 22 & 28 & 78 & 10 & 10 & 14 & 34 \\
\hline ECS & 24 & 20 & 24 & 68 & 0 & 2 & 4 & 6 \\
\hline
\end{tabular}

Considerando que a mediana Pré RV vale 22 e a Pós RV 0, houve melhora nos escores dos aspectos físicos dos voluntários estudados (tabela 1).

Tabela 1 - VALORES DOS ESCORES DO ASPECTO FÍSICO DOS 23 VOLUNTÁRIOS PRÉ REABILITAÇÃO VESTIBULAR (PRÉ RV) E PÓS REABILITAÇÃO VESTIBULAR (PÓS RV)

\begin{tabular}{lcc}
\hline & Pré RV & Pós RV \\
\hline MEDIANA & 22 & $0^{*}$ \\
MÉDIA & 20,96 & 1,39 \\
DESVIO PADRÃO & 4,51 & 2,29 \\
MÍNIMO & 10 & 0 \\
MÁXIMO & 28 & 10 \\
\hline$*$ P $<0.0001$ & & \\
\hline
\end{tabular}


Considerando que a mediana Pré RV vale 22 e Pós RV 6 houve melhora nos escores dos aspectos funcionais dos voluntários estudados (tabela 2).

Tabela 2- VALORES DOS ESCORES DO ASPECTO FUNCIONAL DOS 23 VOLUNTÁRIOS PRÉ REABILITAÇÃO VESTIBULAR (PRÉ RV) E PÓS REABILITAÇÃO VESTIBULAR (PÓS RV)

\begin{tabular}{lcc}
\hline & Pré RV & Pós RV \\
\hline MEDIANA & 22 & $6^{*}$ \\
MÉDIA & 22 & 5,48 \\
DESVIO PADRÃO & 5,9 & 3,43 \\
MÍNIMO & 14 & 0 \\
MÁXIMO & 32 & 14 \\
\hline${ }^{*} P<0.0001$ & & \\
\hline
\end{tabular}

Considerando que a mediana Pré RV vale 22 e Pós RV 6 houve melhora nos escores dos aspectos emocionais dos voluntários estudados (tabela 3).

Tabela 3- VALORES DOS ESCORES DO ASPECTO EMOCIONAL DOS 23 VOLUNTÁRIOS PRÉ REABILITAÇÃO VESTIBULAR E PÓS REABILITAÇÃO VESTIBULAR

\begin{tabular}{lcc}
\hline & Pré RV & Pós RV \\
\hline MEDIANA & 22 & $6^{*}$ \\
MÉDIA & 19,00 & 5,48 \\
DESVIO PADRÃO & 9,06 & 3,87 \\
MÍNIMO & 2 & 0 \\
MÁXIMO & 36 & 12 \\
\hline P<0.0001 & & \\
\hline
\end{tabular}

Considerando que a mediana Pré RV vale 68 e Pós RV 10 houve melhora nos escores dos aspectos gerais dos voluntários estudados (tabela 4). 
Tabela 4- VALOR DOS ESCORES DO ASPECTO GERAL DOS 23 VOLUNTÁRIOS PRÉ REABILITAÇÃO VESTIBULAR E PÓS REABILITAÇÃO VESTIBULAR

\begin{tabular}{lcc}
\hline & Pré RV & Pós RV \\
\hline MEDIANA & 68 & $10^{*}$ \\
MÉDIA & 61,91 & 12,34 \\
DESVIO PADRÃO & 16,13 & 8,77 \\
MÍNIMO & 34 & 0 \\
MÁXIMO & 92 & 34 \\
\hline * $<<0.0001$ & & \\
\hline
\end{tabular}

Foram realizadas as correlações entre a idade dos voluntários estudados e os aspectos físico, emocional, funcional e geral pré e pós $\mathrm{RV}$, onde não pode ser observado a correlação (tabela 5).

Tabela 5 - CORRELAÇÕES ENTRE OS ESCORES DO ASPECTO FÍSICO, EMOCIONAL, FUNCIONAL E GERAL E IDADE

\begin{tabular}{lc}
\hline \multicolumn{1}{c}{ VÁRIAVEIS } & $\mathrm{p}$ \\
\hline Idade X físico pré & 0,05 \\
Idade X físico pós & 0,51 \\
Idade X emocional pré & 0,77 \\
Idade X emocional pós & 0,71 \\
Idade X funcional pré & 0,35 \\
Idade X funcional pós & 0,39 \\
Idade X geral pré & 0,39 \\
\hline Idade X geral pós & 0,51 \\
\hline
\end{tabular}

Posteriormente foram feitas as correlações entre a idade e a diferença de escore pré e pós RV de cada variável, e não foram obtidos dados significantes de correlação (tabela 6). 
Tabela 6- CORRELAÇÕES ENTRE A IDADE E A DIFERENÇA DE ESCORES DO ASPECTO FÍSICO, EMOCIONAL, FUNCIONAL E GERAL PRÉ E PÓS REABILITAÇÃO VESTIBULAR

\begin{tabular}{lc}
\hline \multicolumn{1}{c}{ VÁRIÁVEIS } & $\mathrm{p}$ \\
\hline Idade X diferença (pré - pós) físico & 0,08 \\
Idade X diferença (pré - pós) emocional & 0,91 \\
Idade X diferença (pré- pós) funcional & 0,99 \\
\hline Idade X diferença (pré- pós) geral & 0,44 \\
\hline
\end{tabular}

A associação entre o gênero dos voluntários e a diferença pré e pós RV foi realizada, não havendo associação (tabela 7).

Tabela 7- ASSOCIAÇÕES ENTRE O GÊNERO E A DIFERENÇA DE ESCORES DO ASPECTO FÍSICO, EMOCIONAL, FUNCIONAL E GERAL PRÉ E PÓS REABILITAÇÃO VESTIBULAR

\begin{tabular}{lc}
\hline \multicolumn{1}{c}{ VARIÁVEIS } & $\mathrm{p}$ \\
\hline GÊNERO X DIFERENÇA (PRÉ-PÓS) FÍSICO & 0,58 \\
GÊNERO X DIFERENÇA (PRÉ-PÓS) EMOCIONAL & 1 \\
GÊNERO X DIFERENÇA (PRÉ-PÓS) FUNCIONAL & 0,37 \\
\hline GÊNERO X DIFERENÇA (PRÉ- PÓS) GERAL & 1 \\
\hline
\end{tabular}




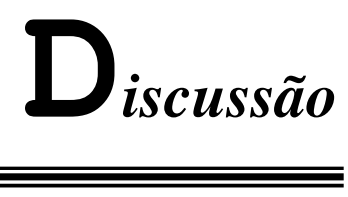




\section{DISCUSSÃO}

Em relação ao gênero dos voluntários estudados, houve uma prevalência quanto ao feminino que representou $17(73,92 \%)$ da amostra total. Esse resultado concorda com outros achados da literatura ${ }^{(49,50,51,52)}$, que afirmam ser a VPPB predominante no gênero feminino. Este achado segundo Guzmán et al. ${ }^{(68)}$ se deve às alterações hormonais que, freqüentemente, ocorrem nas mulheres.

A opção de estudar a ductolitíase de canal posterior se deu pelo fato de não termos observado nenhum caso de cupulolitíase deste canal, o que determinou a população estudada. Frazza et al. ${ }^{(49)}$ encontraram em seu estudo $96,5 \%$ dos casos com substrato fisiopatológico de ductolitíase e apenas 3,5\% dos casos com substrato fisiopatológico de cupulolitíase. O canal semicircular acometido foi o posterior, uma vez que nesta amostra de 23 voluntários não foi observado acometimento do canal horizontal e do superior. $\mathrm{O}$ fato da amostra ser pequena pode explicar a ausência de acometimento do canal horizontal. Pereira \& Scaff ${ }^{(52)}$ justificam tal achado pela posição de proximidade anatômica que o canal posterior tem em relação aos demais, o que facilita o depósito de otólitos soltos em seu interior, enquanto a entrada de debris no canal horizontal é mais raro.

Neste estudo houve uma prevalência de acometimento unilateral, assim como relatado por Ganança et al. ${ }^{(53)}$ e Frazza et al. ${ }^{(49)}$, e a explicação por eles argumentada é que devido a primeira manobra geralmente ser realizada no lado direito, desencadearia vertigem e nistagmos mais intensos do que a segunda, realizada no lado esquerdo. Porém, neste estudo o lado esquerdo $16(69,58 \%)$ foi mais freqüente que o direito $7(30,42 \%)$ o que contradiz os achados relatados pelos mesmos. 
O estudo, ainda, contradiz os achados de Mantello et $a l^{(72)}$ e não foi encontrada explicação na literatura consultada para este achado.

Dos 23 voluntários estudados, 3 (13,04\%) apresentaram de VPPB unilateral porém, os voluntários referiram vertigem bilateral, com presença de nistagmo posicional unilateral e após o tratamento do lado com nistagmo de posicionamento, observou-se a presença do teste de Dix - Hallpike negativo bilateralmente, demonstrando que a VPPB unilateral imitava uma bilateral. Estes achados concordam com os achados de Barreto $^{(73)}$, que relata que se a doença tem manifestação intensa, o paciente pode referir tontura e nistagmo do outro lado também, porém estes serão de muito menor intensidade do que do lado afetado. Existe VPPB bilateral, mas é rara. O tratamento do lado mais acometido leva quase à negativação da manobra dos dois $\operatorname{lados}^{(73)}$.

Dos 23 voluntários tratados $100 \%$ obtiveram alta da RV, porém o número de intervenções necessárias variou de uma a três.

Quanto à quantidade de manobras de Epley utilizadas para o tratamento dos voluntários, $14(60,86 \%)$ necessitaram de uma única manobra, 4 voluntários (17,39\%), foram submetidos a duas manobras e 2 (8,69\%) voluntários necessitaram da aplicação de três manobras de Epley para remissão completa dos sintomas, observada no teste de Dix- Hallpike negativo. Estes achados condizem com os achados de Barreto $^{(73)}$, que relata que a remissão dos sintomas e a negativação do Dix- Hallpike é obtida, na literatura, em 44 a $89 \%$ dos casos com uma única intervenção. Este número aumenta para até $100 \%$ com até 4 intervenções ${ }^{(73)}$.

A manobra de Epley foi utilizada em $100 \%$ dos voluntários, com resultados favoráveis e satisfatórios, pois levou a melhora sintomática, sendo que em 17 
$(73,92 \%)$ dos pacientes a manobra de Epley foi realizada isoladamente, confirmando os resultados encontrados por Froehling et al. ${ }^{(56)}$; Ganança ${ }^{(74)}$; Ganança \& Ganança ${ }^{(37)}$; Pereira \& Scaff ${ }^{(52)}$; Herdman \& Tusa ${ }^{(50)}$; Mantello et al. ${ }^{(72)}$, que relatam um índice acima de $70 \%$ de cura com esta manobra. Seis voluntários $(26,08 \%)$ relataram melhora parcial sendo que, nestes casos, houve a associação da manobra de Epley com os exercícios de Brandt- Daroff. Confirmando os resultados encontrados por Herdman \& Tusa ${ }^{(50)}$, que relatam ausência total dos sintomas em $98 \%$ dos pacientes que usaram a manobra de Brandt- Daroff de 3 a 14 dias após manobra de Epley, todos os pacientes que foram submetidos à manobra de Brandt- Daroff, tiveram melhora em diferentes graus e ausência dos sintomas.

Apesar de um número pequeno de casos observamos um resultado adequado na associação das manobras de Epley e exercícios de Brandt- Daroff sendo que, futuros estudos envolvendo essa associação de manobras devem ser efetuadas.

A RV variou quanto ao tempo de atendimento dos voluntários de 2 a 6 semanas, sendo que $8(34,78 \%)$ dos voluntários necessitaram de 2 semanas de atendimento, $7(30,43 \%)$ precisaram de 3 semanas, $4(17,39 \%)$ realizaram o tratamento em 4 semanas, em $3(13,04 \%)$ o tempo de atendimento foi de 5 semanas e em $1(4,34 \%)$ dos voluntários necessitaram de 6 semanas do início do tratamento à alta.

A monitoração do tratamento, semanalmente, foi realizada por meio do teste de Dix- Hallpike, também realizado para o diagnóstico da VPPB pelo Otorrinolaringologista, determinando o momento da alta, quando este apresentava resultado negativo . Fato este que determinou a importância deste teste em nosso estudo. 
Mesmo sabendo que as recidivas podem ocorrer, após dois anos de cura aparente, apesar de alguns voluntários já terem tido alta há mais de 2 anos, não foram observadas recidivas dos sintomas neste estudo. Contudo faz-se necessário um estudo com um acompanhamento longitudinal destes pacientes pós alta.

O DHI brasileiro neste estudo foi aplicado pré e pós RV com o intuito de tentar quantificar as desvantagens que o paciente com VPPB poderia apresentar em virtude de manifestar a disfunção vestibular nas diferentes variáveis que o teste abrange.

O DHI brasileiro deve ser utilizado em amostras de tamanho mínimo de 9 pacientes, para detectar uma mudança clínica no mesmo, segundo Enloe \& Shields ${ }^{(75)}$ e Roberson \& Irland ${ }^{(76)}$, observaram que os aspectos físico e funcional estiveram mais comprometidos que o aspecto emocional, e nossos achados vão ao encontro dos achados destes autores.

Analisando a qualidade de vida através do questionário (DHI brasileiro), podemos considerar que a reabilitação vestibular proporcionou um incremento da qualidade de vida tanto para a escala física, quanto para a emocional e a funcional, para os voluntários com VPPB avaliados no presente estudo .

O tratamento com a RV nos casos de VPPB, proporcionou melhora estatisticamente significativa na qualidade de vida dos voluntários neste estudo, sendo que este resultado foi determinado pela análise estatística de dados emparelhados do questionário de handicap para a tontura tanto na escala geral como nas escalas física, emocional e funcional.

Foram efetuadas correlações entre a idade dos voluntários e os escores geral, físico, funcional e emocional pré e pós reabilitação vestibular, onde se observou uma 
tendência à correlação inversa entre a idade e o aspecto físico Pré- RV, isto significa que quanto maior a idade houve menos comprometimento do aspecto físico pré tratamento. Analisando os dados das anamneses verificou-se que um dos voluntários apresentava idade de 91 anos e obteve escore zero no aspecto físico ou seja não apresentava queixas. Este achado explica, pelo menos em parte, esta tendência de correlação. Provavelmente com o aumento da população estudada esta correlação desapareceria.

Deste modo, levando em conta os dados epidemiológicos do envelhecimento que mostram um crescimento da população de idosos e, sabendo que são as pessoas desta idade as acometidas de VPPB, a reabilitação vestibular poderia ser utilizada no tratamento desta afecção com impacto benéfico na qualidade de vida destes idosos.

Este trabalho indica, por fim, a necessidade de ampliar a divulgação entre os fonoaudiólogos e o meio médico dos benefícios conquistados pela RV em pacientes com VPPB de canal posterior por ductolitíase. 


\section{CONCLUSÃO}

A partir da análise crítica dos resultados obtidos e baseando nos objetivos propostos pode-se concluir com este estudo, que as manobras utilizadas no tratamento da VPPB por meio da Reabilitação Vestibular foram eficientes no tratamento dos voluntários, devido aos resultados do teste de Dix- Hallpike negativo pós manobra (teste que monitorou o tratamento) e alta dos pacientes assintomáticos. A manobra de Epley foi a manobra mais utilizada no atendimento dos voluntários, sendo necessário uma única manobra para o reposicionamento dos otólitos em 17 $(73,92 \%)$ dos voluntários.

Concluiu-se, também, que nos voluntários estudados o tempo (em semanas) de duração da reabilitação vestibular para o tratamento da VPPB foi de 2 (34,78\%) a $6(4,75 \%)$ semanas, sendo que com uma ligeira predominância para 2 semanas de tratamento.

Os valores dos escores do aspecto físico pré e Pós RV demonstram melhora, uma vez que a mediana pré RV apresentou valor de 22 e pós RV esse valor foi zero.

$\mathrm{O}$ aspecto funcional pré e pós $\mathrm{RV}$ apresentou melhora, modificando a mediana de seus escores de valor 22 para seis, pré e pós RV, respectivamente.

Quanto ao aspecto emocional pré e pós RV concluiu-se melhora deste aspecto quando comparamos os escores pré RV que tem valor 22 e pós RV que tem valor seis.

O DHI brasileiro no seu aspecto geral apresentou melhora pré RV em comparação a este mesmo aspecto pós RV pois seus valores modificaram de 68 para 10. 
Considerando-se os resultados obtidos no DHI brasileiro pós RV, pode-se dizer que a reabilitação vestibular utilizada mostrou-se eficaz quando comparada com o DHI brasileiro inicial em virtude das habilidades readquiridas pelos voluntários no final do processo terapêutico. 


\section{Referências Bibliográficas}




\section{REFERÊNCIAS BIBLIOGRÁFICAS}

1- Cançado FAX. Epidemiologia do envelhecimento. In: Cançado FAX. Noções Práticas de Geriatria. Belo Horizonte: Coomed editora/Health C.R. Ltda., 1994.

2- Instituto Brasileiro de Geografia e Estatística- IBGE, 1996. Disponível em www.ibge.org.br. Acesso em 2000.

3- Berquó ES \& Leite VM. Algumas considerações sobre a demografia da população idosa no Brasil. SP, Ciência e Cultura, 40 (\&): 679-688,1980.

4- Moriguti JC. Avaliação do efeito da sobrecarga de Arginina sobre a resposta imune em Idosos. Dissertação apresentada à Faculdade de Medicina de Ribeirão Preto da Universidade de São Paulo para obtenção do título de Doutor na área de concentração: Clínica Médica. Ribeirão Preto, 1998.

5- Albernaz MPL, Ganança MM. Vertigem. Introdução. In: Costa SS, Cruz OLM, Oliveira J AA et al. Otorrinolaringologia - Princípios e Prática. Artes médicas. Porto Alegre, 1994. Cap.24, p.232.

6- Ganança MM, Caovilla HH, Ganança FF. Como lidar com a vertigem no idoso. São Paulo: Janssen-Cilag; 1996. 
7- Ganança MM, Caovilla HH, Munhoz MSL, Silva MLG, Frazza MM. As etapas da equilibriometria: nistagmo de posição e nistagmo posicional. In: Ganança MM, Caovilla HH, Munhoz MSL, Silva MLG. . Equilibriometria clínica. Atheneu, São Paulo, 1999.

8- Holstein BE, Almind G, Due P, Holst E.. Self-reported heathstatus and drugs use a elderly. Ugeskr Laeger 1990; 152:386-91.

9- Katsarkas A. Dizziness in aging: a retrospective study of 1194 cases. Otolaryngol. Surg 1994; 110:296-301.

10- Vilárquez- Villaseñor L, Merchant SN, Tsuji K, Wall C, Merchant SN, Glynn RJ, Rauch S. Temporal bone studies of the human periphral vestibular sistem. Normative Scarpa's ganglion cell data. Ann Otol. Rhinol Laryngol suppl 2000;181:14-9.

11- Ganança FF, Taguchi CK, Moura PC, Bushatskay A. O que é Reabilitação Vestibular? 1997; 2:93-100.

12- Cohen H. Vestibular rehabilitation reduces functional disability. Otolaryngol. Head Neck Surg, 1992.

13- Araújo F. Vertigem no Idoso. In: Cançado FAX. Noções Práticas de Geriatria. Belo Horizonte: Coomed editora/Health C.R. Ltda., 1994. 
14- Ganança MM, Caovilla HH, Munhoz MSL, Silva MLG. Alterações da audição e do equilíbrio corporal no idoso. Revista Brasileira de Medicina. v. 56, n 10., Out.1999a. Disponível em: File://A:\RBM-Alterações da audição e do equilíbrio corporal no idoso.htm. Acesso: 10/09/00.

15- Hain TC, Ramaswamy TS, Hillman MA. Anatomia e fisiologia do sistema vestibular normal. In: HERDMAN, S.J. Reabilitação Vestibular. São Paulo: Manole, 2002.

16- Hain TC. Benign paroxysmal positional vertigo. Northwestern University Medical School, Chicago, ILL, USA. Disponível em :

http://www.tchain.com/otoneurology/disorders/bppv/bppv.html. Acesso:20.jun.2002.

17- Oliveira AA.Determinação dos Parâmetros vestibulares normais à videonistagmografia.2002,p.9. Dissertação apresentada à faculdade de Medicina de Ribeirão Preto da Universidade de São Paulo para obtenção do título de mestre em medicina, área de otorrinolaringologia. Ribeirão Preto, 2002.

18-Barbosa MSM, Ganança FF, Caovilla HH, Ganança MM. Reabilitação Labiríntica: o que é e como se faz. Otorrinolaringologia, v.II, n.1, p. 24-34, Janeiro, 1995. 
19- Dodge R.- Habituation to rotation. J. Exp. Psychol., 6: 1-35, 1923.

20- Macbe BF. Vestibular Suppression in figure skaters. Trans. Amer. Acad. Ophthal. Otolaryngol., 64: $264-8,1960$.

21- Boussens JS, Vorsin HP. Reeducation de l'équilibration. Revue de Laringologie, $989-10): 443-7,1977$.

22- Dix MR.- The physiological basic and pratical value of head exercises in the treatment of vertigo. Practitioner, 217, 1976.

23- Norré ME \& De Weerdt W.- Vestibular habituation training; tecnique and first results. Acta Oto- Rhynol-Laryngol. Belg, 33 (3): 347-69,1979.

24- Brandt T \& Daroff R B.- Physical therapy for benign paroxysmal vertigo. Arch Otolaryngol., 106: 484-5,1980.

25- Semont A, Freyss G, Vitte E.- Curing yhe BPPV with a liberatory maneurer. Adv. Otorhinolaryngol., 42: 290-3, 1988.

26- Epley JM.- The canalith repositioning procedures for treatment of benign positional vertigo. Otolaryngol. Head Neck. Surg., 107:399-404, 1992. 
27- Sherpard NT. -New approaches to the dizzy patient; referral investigation and treatment. London, BSA London Evening Meeting, 1995. (April)

28- Pedalini MEB, Bittar RSM. Reabilitação Vestibular: Uma proposta de trabalho. Rev. Pró Fono, v. 11, n. 1, p.140-4, Março, 1999.

29- Brian C, Boussens J \& Voisin HP. La Rééducation des handicaps vestibularies, Rewe de Layngologie, vol.95, n 9-10, 1974.

30- Cawthone T. The physiological basis of head exercises. J. Chart. Soc.physiother., 106-7,1944.

31- Cooksey FS. Rehabilitation in vestibular injuries. Proc. Royal Soc. Med., 39:273$8,1946$.

32- Ganança MM, Caovilla HH. O Universo das tonturas no idoso: desafios e soluções. Atualidades em Geriatria 2(7): 22-8,1996.

33- Hamid MA. Cupulolithiasis versus canalolithiasis: A new Hypothesis. Abstract. Presented at the ANS Society Meeting, Scottsdate, AZ, May, 1997.

34- El Kashlan HK, Sherpard NT, Ascher AH, Smith-Wheelock M, Telian AS.Evaluation of clinical measures of equilibrium. Laringoscope, 108 (3): 311-19, 1998. 
35- Amá LAG, Oliveira MCAGC. Reabilitação Vestibular- nossa experiência. Ver. Bras. De Otorrinolaringologia, v. 60 n.2, p. 113-116, 1994

36- Konnur MK. Vertigo and vestibular rehabilitation. J. Postgrad Med., Ïndia, v. 46, n.3, p. 222-3, 2000.

37- Ganança FF, Ganança CF. Reabilitação vestibular: princípios e técnicas. In: Ganança MM, Munhoz MSL, Caovilla HH, Silva MLG. Estratégias terapêuticas em otoneurologia. São Paulo: Atheneu, 2001.

38- Zeigelboim BS, Frazza MM, Boagio M, Caovilla HH, Ganança MM. Reabilitação labiríntica em instituições. In: Lagrotta MGM, César CPHAR. A fonoaudiologia nas instituições- São Paulo, Lovise, 1997. Cap. 9, p. 71-5.

39- Caovilla HH, Ganança MM, Munhoz MSL, Silva MLG, Ganança FF, Ganança CF. As labirintopatias mais freqüentes. Revista Brasileira de Medicina 57, 149 152, dez.2000.

40- Maudonnet EN, Maudonnet OQ. Reabilitação vestibular-bases neurofisiológicas. Revista Acta Awho, v. 19, n.4, p. 189-192, out/dez.2000.

41- Bohlsen Y, Torres MLB. Apostila do curso básico: Otoneurologia- Reabilitação Vestibular. São Paulo, 1999. 
42- Berthoz A \& MelvillJones G. Adaptive Mechanisms in gaze control: Facts and Theories. Elsevier. Amsterdam, 1985.

43- Bárány R. - Diagnose von Krankheitserscheinungen in bereiche des otollithebapparates. Acta Otolaryngol. (stockholm),1921; 2:437-47.

44- Dix R \& Hallpike C S. The Pathology, symptomatology and diagnosis of certain. Common disorders of the vestibular System. Proc. R. Soc Med. 1952.

45- Paparella MM, Costa SS, Cruz OLM. In: Costa SO, Cruz OLM, Oliveira JAA et al. Otorrinolaringologia - Princípios e Prática. Porto Alegre: Artes médicas, 1994. Cap.25, p.245-246.

46- Schuknecht, H. F.- Cupulolithiasis. Arch Otolaryngol., 1969.; 90: 765-778.

47- Ganança MM, Caovilla HH. Reabilitação vestibular personalizada In: Ganança MM. Vertigem tem Cura? São Paulo: Lemos Editorial,1998.

48- Cohen HS, Jerabeck J. Efficacy of treatments for posterior channel benign paroxysmal positional vertigo. Laryngoscope, v. 1099, n. 4. USA, p. 584-590, April, 1999. 
49- Frazza MM, Caovilla HH, Ganança MM, Cabete CS, Munhoz MSL, Silva MLG. Da direção do nistagmo de posicionamento na vertigem posicional paroxística benigna. Revista Acta Awho, v.20, n.3, p. 141,146, jul./set. 2001.

50- Herdman SJ, Tusa RJ. Avaliação e tratamento dos pacientes com VPPB. In: Herdman S.J. Reabilitação Vestibular. São Paulo: Manole, 2002.

51- Ganança MM, Caovilla HH, Ganança FF, Munhoz MSL, Silva MLG.- Vertigem Posicional Paroxística Benigna. In: Silva MLG, Munhoz MSL, Ganança MM, Caovilla HH.- Quadros Clínicos Otoneurológicos mais Comuns. São Paulo, Atheneu, 2000, p. 9-19.

52- Pereira CB, Scaff M. Vertigem de posicionamento paroxística benigna. Arquivos de neuropsiquiatria, v. 59, n. 2B, p. 466-470, jun. 2001.

53- Ganança MM et al. Como diagnosticar e tratar as vestibulopatias mais freqüentes. Revista Brasileira de Medicina: Caderno de Otorrinolaringologia, v. 57, n. 12, dez., 2000. Disponível em: http://www.cibersaude.com.br/revista.asp. Acesso: 20. Nov.2001.

54- Ford-Smith CD.- The individualized treatment in rehabilitation treatment of vertigo and dizziness. Acta Awho XI (1): 31-43, 1992. 
55- Hall SF, Ruby SRF, McClure JÁ. The mechaniscs of benign paroxysmal vertigo. J. Otolaryngol 8:151, 1979.

56- Froehling DA, Bowen JM, Mohr DN, Brey RH, Beatty CW, Wollan PC, Silzerstein MD. The canalith repositioning procedure for the treatment of Benign Paroxysmal Positional Vertigo: a randomized controlled prial. Rochester, Maya Clinic Proc, v.75, n. 7, p. 695-700, jul.2000.

57- Amá LAG, Oliveira MCAGC. Um Método de Reabilitação para pacientes com problemas de equilíbrio: Reabilitação vestibular. In: Marchesan IQ, Zorzi, JL.; Gomes ICD Org. Tópicos em fonoaudiologia. São Paulo, Lovise, 1996. Cap.35.p.557-561.

58- André APR. Protocolo de anamnese. Hospital das Clínicas da faculdade de Medicina de Ribeirão Preto, Setor de Fonoaudiologia. Elaborado em 1999.

59- Ganança CF, Dias SFG, Ganança MM. Orientação nutricional e mudanças de hábito do paciente vertiginoso. In: Ganança MM, Munhoz MSL, Caovilla HH, Silva MLG. Estratégias terapêuticas em otoneurologia. São Paulo: Atheneu, 2001.

60- Albernaz PLM. Doenças metabólicas da orelha interna. Revista Brasileira de Otorrinolaringologia. 2 (1): 18 - 22, jan. 1995. 
61- Ruckenstein MJ. Eficácia terapêutica da manobra de Epley para reposição canalicular. Laringoscope. June/ 2001.

62- Aburto A, Medrano MLV, Torre JI. Rehabilitación. Vestibular en el VPPB. Ver. Otorrinolaringol. Cir. Cabeza Cuello. v 62,p. 123-128, 2002

63- Serafini F, Ganança MM, Caovilla HH, Munhoz MS, Silva MLG, Ganança FF, Ganança CF. Reflexões sobre a Farmacoterapia da vertigem: Problemas e Soluções. Parte II - Atualidades... Revista Brasileira de medicina - Atualização em Otorrinolaringologia, 5 (2): 46 - 9, 1998.

64- Lavinsky L. Cirurgia da Vertigem. In: Costa e cols. OtorrinolaringologiaPrincípios e Prática. Cap. 27 p. 257.Artes Médicas. Porto Alegre:1994.

65- Gacek RR. Singular Neurectomy update. Ann Rhinol. Laryngol., 91: 469-73, 1982.

66- Nuti, D, Agus G.; Barbieri MT, Passali, D. The management of horizontal canal paorxysmal positional vertigo. Acta Otolaryngol. (Stockh), Siena, V. 118, p. 455-460, 1998.

67- Maia RA, Diniz F L, Carlesse A. Manobras de reposicionamento no tratamento da VPPB. Revista Brasileira de Otorrinolaringologia, v.65, n. 5, p. 612-616, set/out. 2002. 
68- Guzmán PV, Zeigelboim BS, Hassan SE, Frazza MM, Diniz Jr J, Caovilla HH. A manobra de Brandt- Daroff modificada na reabilitação da vertigem postural. Revista Acta Awho, v. 19, n. 4, p. 189- 192, out./dez. 2000.

69- André APR, Rosin MV, Colafêmina JF. A efetividade da reabilitação vestibular na vertigem postural paroxística benigna. In: IV International Symposium on Transplants and Implantas in Otology, I Internacional Symposium and Updating in Dizziness and Tinnitus, Updating Symposium on Hearing Devices. Anais... São Paulo: Associação Willian House de Otologia, 2001.

70- Jacobson GP, Newman CW. The development of yhe dizziness handicap inventory. Arch Otolaryngol. Head and Neck surg. 21:234-45, 1990.

71- Castro AS, Ganança FF, Branco FCA, Natour J. Dizziness Handicap Inventory: adaptação cultural para o português brasileiro, aplicação e reprodutibilidade e comparação com os resultados à vestibulometria [tese]. São Paulo: Universidade Bandeirante de São Paulo;2003.

72- Mantello EB, Aquino AMCM, André APR.- A reabilitação vestibular na vertigem postural paroxística benigna. Trabalho de conclusão de Curso apresentado como exigência parcial, para obtenção de grau no curso de fonoaudiologia da Universidade de Franca. Franca, 2002. 
73- Barreto ACP. Vertigem posicional paroxística benigna (VPPB) no idoso. Serviço de Geriatria do Hospital das Clínicas da faculdade de Medicina da Universidade de São Paulo. Disponível em: http://geocities.com/geriatriac/vertigem.html. Acesso em 09/08/02.

74- Ganança, MM. VPPB: como diagnosticar e tratar. Revista de Otorrinolaringologia, v. 7, n. 3: Nov. 2000 a. Disponível em: http://www.cibersaúde.com.br/revistas.asp. Acesso: 10/09/00.

75- Enloe LJ, Shieds RK. Evaluation of helth- related quality of life in individuals with vestibular disease using disease- specific and general outcome measuares. Phys Ther, 1997.

76- Roberson DD, Ireland DJ. Dizziness Handicap Inventory Correlate of computerize posturography. J. Otolaryngol, 1995: 24:118-24. 
$\mathbf{A}_{\text {nexos }}$ 


\section{ANEXOS}

\section{ANEXOS A - Carta de Aprovação do Trabalho no Comitê de Ética em Pesquisa}

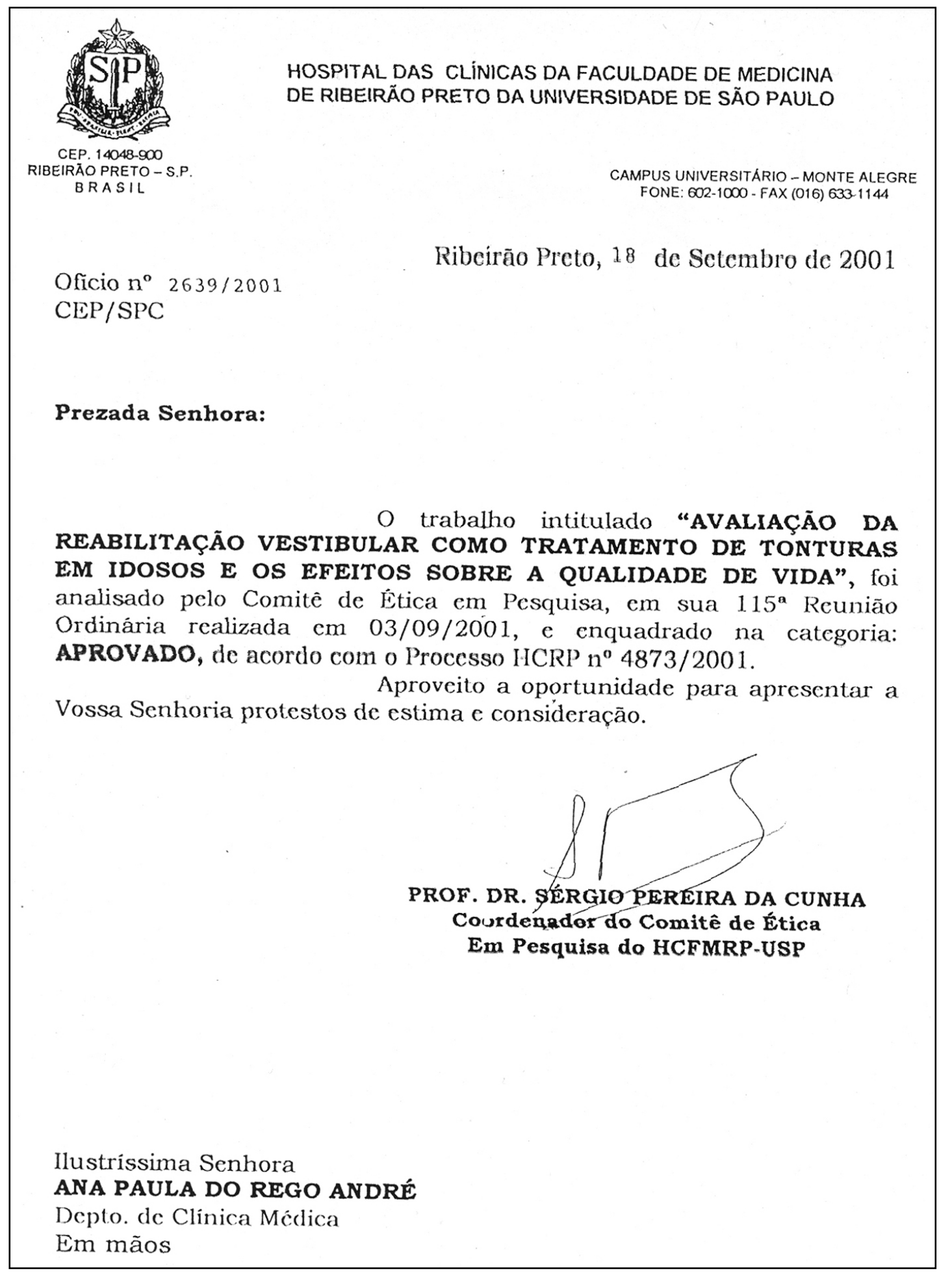




\section{ANEXO B - Termo do consentimento livre e esclarecido}

$\mathrm{Eu}$ abaixo assinada, tendo sido devidamente esclarecido sobre todas as condições que constam do documento "ESCLARECIMENTO AO SUJEITO DA PESQUISA", de que trata o Projeto de Pesquisa intitulado Avaliação da Reabilitação Vestibular como tratamento de tonturas em idosos e os efeitos sobre a qualidade de vida que tem como pesquisadora responsável a Sra. Ana Paula do Rego André especialmente no que diz respeito ao objetivo da pesquisa, aos procedimentos que serei submetido, aos riscos e aos benefícios, à forma de ressarcimento no caso de eventuais despesas, bem como a forma de indenização por danos decorrentes da pesquisa, declaro que tenho pleno conhecimento dos direitos e das condições que me foram assegurados, a seguir relacionados:

A garantia de receber a resposta a qualquer pergunta ou esclarecimento de qualquer dúvida a respeiro dos procedimentos, riscos, benefícios e de outras situações relacionadas com a pesquisa e o tratamento a que serei submetida.

1. A liberdade de retirar o meu consentimento e deixar de participar do estudo, a qualquer momento, sem que isso traga prejuízo à continuidade do meu tratamento.

2. A segurança de que não serei identificado e que será mantido o caráter confidencial da informação relacionada à minha privacidade.

3. O compromisso de que me serão prestadas informações atualizadas durante o estudo, ainda que estas possam afetar a minha vontade de continuar dele participando.

4. O compromisso de que serei devidamente acompanhada e assistida durante todo o período de minha participação no projeto, bem como de que será garantida a continuidade do meu tratamento, após a conclusão dos trabalhos da pesquisa.

Declaro, ainda, que concordo inteiramente com as condições que me foram apresentadas e que, livremente, manisfesto a minha vontade em participar do referido projeto.

Ribeirão Preto, de de 


\section{ANEXO C - Anamnese}

\section{IDENTIFICAÇ̃̃O}

Nome:

Registro n. ${ }^{\text {: }}$ :

Hipótese diagnóstica:

Idade:

Principal queixa:

Encaminhado por:

\section{Característica dos episódios de tontura:}

Há quanto tempo:

Duração de cada episódio:

Último episódio:

Ocorre em alguma hora do dia:

Como se sente entre os episódios:

Apresentou incapacidade social: ( número de vezes que ficou afastado das atividades profissionais e sociais devido a tontura)

Sente insegurança física:

Já teve depressão:

Se sente prejudicado pela tontura:

A tontura limitou de alguma forma sua vida ( profissional e social):

A tontura fez com que você saísse menos que gostaria:

A tontura faz você sentir-se triste ou deprimido: 
Andar no corredor do supermercado piora o problema:

Sabe ler? Esta tendo dificuldade para ler:

Tem medo de sair de casa sem companhia:

Evita lugares altos:

Dificuldade de andar pela casa no escuro:

$\underline{\text { Sintomas relacionados a tontura: }}$

Vertigem :

Cabeça zonza:

Desvio da marcha:

Para qual direção:

Desmaios:

Tendência a cair:

Perda de equilíbrio ao caminhar:

Sintomas relacionados a tontura:

Náusea:

Sudorese:

Palidez:

Visão dupla:

Dor de cabeça:

Fatores desencadeantes:

Girar a cabeça:

Movimentos rápidos:

Virar a cabeça para os lados:

Abaixar e levantar: 
Sentar e levantar:

Estender roupa:

Virar na cama:

$\underline{\text { Manifestações auditivas: }}$

Diminuição da audição: OD OE

Ruído nos ouvidos: OD OE

Secreção nos ouvidos: OD OE

Cirurgia nos ouvidos: OD OE

O zumbido muda quando sente as tonturas:

Pressão nos ouvidos:

Dor nos ouvidos:

Bebe algum tipo de bebida alcóolica:

Fuma:

Usa algum medicamento:

Faz algum tipo de esporte:

Tem algum problema visual:

Dieta:

Coca-cola:

Café:

Chá mate e chá preto:

Auto medicação:

OBS: Protocolo de anamnese elaborada pela fonoaudióloga Ana Paula do Rego André em 1999, para o Setor de Fonoaudiologia do HCFMRP-USP 


\section{ANEXO D - DIZZINESS HANDICAP INVENTORY (DHI brasileiro)}

\section{DIZZINESS HANDICAP INVENTORY (DHI brasileiro)}

(Jacobson \& Newman, 1990)

DATA 1

Obs.:

\begin{tabular}{|c|c|c|c|}
\hline & $\mathbf{N}$ & ITEM & $\begin{array}{l}\text { Sim/Não/ } \\
\text { Às vezes }\end{array}$ \\
\hline 1 & FI & Olhar para cima piora o seu problema? & \\
\hline 2 & EM & Você se sente frustada (o) devido ao problema? & \\
\hline 3 & FU & Você restringe suas viagens de trabalho ou lazer por causa do problema? & \\
\hline 4 & FI & Andar pelo corredor do supermercado piora o seu problema? & \\
\hline 5 & FU & Devido ao seu problema você tem dificuldades ao deitar-se ou levantar-se & \\
\hline 6 & FU & $\begin{array}{l}\text { Seu problema restringe significativamente sua participação em atividades sociais } \\
\text { tais como: sair para jantar, ir ao cinema, dançar ou ir a festas? }\end{array}$ & \\
\hline 7 & FU & Devido ao seu problema você tem dificuldade para ler? & \\
\hline 8 & FI & $\begin{array}{l}\text { Seu problema piora quando você realiza atividades mais difíceis como esportes, } \\
\text { dançar, trabalhar em atividades domésticas tais como: varrer e guardar a louça? }\end{array}$ & \\
\hline 9 & EM & $\begin{array}{l}\text { Devido ao seu problema, você tem medo de sair de casa sem ter alguém que o } \\
\text { acompanhe? }\end{array}$ & \\
\hline 10 & EM & $\begin{array}{l}\text { Devido ao seu problema, você se sente envergonhado na presença de outras } \\
\text { pessoas? }\end{array}$ & \\
\hline 11 & FI & Movimentos rápidos da sua cabeça pioram o seu problema? & \\
\hline 12 & FU & Devido ao seu problema você evita lugares altos? & \\
\hline 13 & FI & Virar-se na cama piora o seu problema? & \\
\hline 14 & FU & Devido ao seu problema, é difícil fazer trabalho pesado, em casa ou no jardim? & \\
\hline 15 & EM & $\begin{array}{l}\text { Por causa do seu problema, você teme que as pessoas achem que está drogado (a), } \\
\text { bêbado (a)? }\end{array}$ & \\
\hline 16 & FU & Devido ao seu problema, é difícil para você sair para caminhar sem ajuda? & \\
\hline 17 & FI & Andar numa calçada piora o seu problema? & \\
\hline 18 & EM & Devido ao seu problema, é difícil para você se concentrar? & \\
\hline 19 & FU & Devido ao seu problema, é difícil para você andar pela casa no escuro? & \\
\hline 20 & EM & Devido ao seu problema , tem medo de ficar em casa sozinha (o)? & \\
\hline 21 & EM & Devido ao seu problema, você se sente incapacitado? & \\
\hline 22 & EM & Seu problema prejudica suas relações com membros de sua família ou amigos? & \\
\hline 23 & EM & Devido ao seu problema, você está deprimida? & \\
\hline 24 & FU & Seu problema interfere em seu trabalho ou responsbilidades em casa? & \\
\hline 25 & FI & Inclinar-se piora o problema? & \\
\hline
\end{tabular}

\begin{tabular}{|c|c|c|c|}
\hline FÍSICO & EMOCIONAL & FUNCIONAL & TOTAL GERAL \\
\hline 128 & 136 & 136 & $/ 100$ \\
\hline
\end{tabular}

Legenda: FI- Aspecto físico/ FU- Aspecto funcional/ EM - Aspecto emocional

Pontuação: a cada resposta: sim 4 pontos; às vezes 2 pontos; não $=0$ pontos 